\title{
Large-Signal Microwave Characterization of AlGaAs/GaAs HBTs based on a Physics-Based Electro-Thermal Model
}

\author{
Christopher M. Snowden, Fellow \\ Microwave and Terahertz Technology Group, \\ Department of Electronic and Electrical Engineering, \\ University of Leeds, Leeds, LS2 9JT. UK
}

\begin{abstract}
A physics-based multi-cell electro-thermal equivalent circuit model is described which is applied to the large-signal microwave characterization of $\mathrm{AlGaAs} / \mathrm{GaAs}$ HBTs. This highly efficient model, which incorporates a new multi-finger electro-thermal model, has been used to perform DC, small-signal and load-pull characterization and investigate parameter-spreads due to fabrication process variations. An enhanced Newton algorithm is presented for solving the non-linear system of equations for the model and associated circuit simulator, which allows a faster and more robust solution than contemporary quasi-Newton non-linear schemes.
\end{abstract}

\section{INTRODUCTION}

Heterojunction bipolar transistors have demonstrated high power output densities at microwave frequencies and are increasingly being utilized for large-signal applications such as power amplifiers, oscillators and mixers $[1,2,3]$. The design of these circuits is challenging because of their non-linear behaviour and accurate large-signal models are required to expedite this process. In the case of HBTs, the high power densities associated with these devices can lead to significant operating temperatures when the transistor is used in large-signal applications. Although the temperature sensitivity of transistor parameters is significant for all types of power transistor it is particularly important for the HBT with its high associated power densities, relatively poor thermal conductivity and strong dependence of junction behaviour on temperature. This means that it is essential to characterise the large-signal model of the HBT as a function of operating and ambient temperatures in order to obtain an accurate model for CAD. Finally, there are a number of advantages in relating the operation of the device to the structure and transport properties of the transistor. In particular, this allows the design of the device to be optimized for a particular application and the model can be used to predict the parameter spreads for a particular 
design and fabrication process. In the case of power transistors, with many emitter fingers distributed throughout a repeating cell structure, Figure 1, it is desirable to model the electrical and thermal aspects of individual cells, which may vary across the structure. This generally requires a physical model.

Detailed two-dimensional physical models, which solve a set of transport equations have been reported (for example [4,5]) and provide a valuable insight in to the physics behind the operation of HBTs. However, there are a number of issues which still to be addressed to obtain good quantitative correlation between these physical models and measured data (including hot electron effects, representation of hetero-transport properties, processing dependent junction ideality factors and saturation currents). Furthermore, although these models are suitable for modern workstations, they still require substantial computation time to execute single bias point simulations and are unsuitable for microwave computer-aided-design. An attractive alternative which combines some of the advantages of physical models with the relative simplicity of implementation of equivalent circuit models is found in physics-based models, where the element values can be related to the structure and semiconductor properties of the device.

This paper describes a physics-based multi-cell electro-thermal HBT model, Figure 2, which can be used to predict the performance of the transistor for DC, small- and large-signal modes of operation. It is suited to process-oriented design. The model has been integrated into a harmonic-balance simulator to perform simulated load-pull characterization of power transistors. The results obtained from this analysis are compared with measured data obtained for prototype devices. An enhanced Newton algorithm is presented which allows very rapid convergence of the non-linear solution algorithm compared with contemporary modified-Newton schemes. Finally, a novel multi-finger coupled electro-thermal model based on a thermal resistance matrix concept is described which accounts for local heating and thermal run-away effects.

\section{Physics-Based Equivalent Circuit Model}

A number of large-signal equivalent circuit HBT models have been described in the literature $[6,7,8,9]$, 
including notable examples of physics-based model and modified SPICE bipolar transistor models [10]. However, few of these have accounted for the process-dependent nature of the transistor and require extensive microwave and DC data to extract the element values. In other cases the complexity of the model leads to difficulties in obtaining fully converged solutions from the non-linear solver and additional convergence problems when used in association with harmonic-balance algorithms.

Ebers-Moll representations have been produced for microwave HBT's ([11,12] are good examples), but they are usually empirical in nature and are again difficult to relate to device structure and material parameters. The Gummel-Poon model, which is essentially a charge-control model, provides a superior representation in terms of the physical operation compared with the basic Ebers-Moll model, remaining valid in the high injection regime and including recombination effects present in the space-charge regions. However, the basic Gummel-Poon model it is not directly applicable to HBTs, because the base current in HBTs is dominated by surface or junction space charge region (SCR) recombination, rather than hole injection from the base into the emitter as in BJTs. Furthermore, the base current at low current densities is mainly due to surface recombination $[13,14]$. The temperature dependence of the equivalent circuit element values suggests that the base current at high current densities is largely attributable to SCR recombination. A consequence of this is that the ideality factor of base current is always higher than the ideality factor of the collector current. This results in two regions of increasing current gain in the HBT, defined by the component of base current that is dominant in each region (surface or bulk recombination). This contrasts with the classical Gummel-Poon model, where the current gain increases initially, flattens and then decreases with increasing $V_{\mathrm{BE}}$.

On the basis of investigations performed using two-dimensional numerical models it was found appropriate during the development of the model described here to neglect hole injection into the emitter from the base; recombination through deep levels in the base-emitter space-charge region; hole injection into the collector from the base; and recombination through deep levels in the base-collector space charge region. Emitter crowding is negligible in HBT's, unlike the situation in BJTs. These results in a useful simplification of the model without compromising the accuracy from the point of view of microwave 
The electrical equivalent circuit model of one emitter 'cell' of an HBT, developed during this work is shown in Figure 3, and can be considered in terms of forward and reverse current components. This diagram shows the six ideal diodes which describe the behaviour of the transistor junctions. The forward and reverse base current has two components - the SCR recombination (described by $I_{\mathrm{SE}}, N_{\mathrm{E}}$ and $I_{\mathrm{SC}}, N_{C}$ for $D_{B E O}$ and $D_{B C O}$ respectively) and the surface recombination (described by $I_{\mathrm{SES}}, N_{\mathrm{ES}}$ and $I_{\mathrm{SCS}}, N_{\mathrm{CS}}$ for $D_{B E S}$ and $D_{B C S}$ respectively ). The electron injection into the base from the emitter is modelled by the diode $D_{F} \quad\left(I_{\mathrm{SF}}, N_{\mathrm{F}}\right)$ and the electron injection into the base from the collector by the diode $D_{R}\left(I_{\mathrm{SR}}, N_{R}\right)$. This arrangement of six diodes allows the diode parameters to assume physically meaningful values across the full range of bias conditions in contrast to HBT models utilizing four diodes. The latter cannot satisfactorily model surface recombination and often lead to compromised fits to Gummel data, when the full range of currents are considered. The electron injection into the base is characterized by ideality factors close to unity $\left(N_{F}\right.$ and $\left.N_{R}\right)$. The surface recombination components typically have ideality factors in the region of 1.6 to $2\left(N_{\mathrm{ES}}\right.$ and $\left.N_{\mathrm{CS}}\right)$. The thermal voltage $V_{\mathrm{Ti}}\left(k T_{i} / q\right)$ in the diode equations (Table 1) reflects the temperature $T_{\mathrm{i}}$ of the individual cell $i$, associated with the diodes in the model for each cell. Note that the diode currents are functions of the intrinsic base-emitter and base-collector voltages $\mathrm{v}_{\mathrm{BE}}$ and $\mathrm{v}_{\mathrm{BC}}^{\prime}$ respectively of each cell.

The saturation currents and ideality factors associated with the ideal diodes which model the junctions are very sensitive to processing conditions and have proven difficult to unambiguously extract from physical models, although recently reported results indicate that such an extraction is feasible [15]. Forward and reverse Gummel plots $(\log (I) / V) \quad$ [16] are used to determine the diode parameters, shown in Table 1. The temperature of the transistor must be accurately determined and maintained during the duration of the measurement (saturation currents change by approximately $21 \%$ per $\mathrm{K}$ ). If accurate temperature measurement is not possible, the average device temperature $T$ can be estimated by assuming an idealised exponential characteristic for the base-collector junction (where $N_{R}$ is assumed to be unity), when the device is operating in the reverse mode $\left(\exp \left(V_{\mathrm{BC}} / V_{\mathrm{T}}\right)\right)$. The average device temperature can be 
extracted from the reverse characteristics using $T=\frac{q}{k} \frac{\partial V_{B C}}{\partial \ln \left(I_{E}\right)}$. A constant device temperature can be achieved using pulse-measurement capability to avoid self-heating, with the device held in a temperature stabilized environment (such as a temperature controlled oven or probe-station stage). The saturation current $I_{\mathrm{S}}$ can be obtained by determining the intercept of the $\log (I)$ axis, corresponding to $V_{\mathrm{B}}=0 \mathrm{~V}$ and the ideality factor $N$ is determined from the gradient of the collector current characteristic using $N=$ $1 /\left(\right.$ gradient. $\left.\ln (10) \cdot V_{\mathrm{T}}\right)$. A typical measured forward Gummel plot of an AlGaAs/GaAs HBT is shown in Figure 4. The deviation in $I_{\mathrm{C}}$ at low current levels is due to limited sensitivity in the measurement system. At high current levels the characteristics bend principally as a consequence of voltage dropped across the base and emitter resistances. One of the difficulties encountered in extracting the saturation currents and ideality factors from measured data is the sensitivity to the 'choice' of line used to approximate the characteristic if a manual estimation is made by simple inspection. A superior method of determining these values is to use singular value decomposition (SVD) in association with a least squares fit. The SVD method of extracting HBT parameters was used by Hafizi et al [14], who developed an iterative least squares fitting technique to extract the transistor diode and current gain parameters. A singular value decomposition (SVD) matrix factorization technique $[14,17]$, is used in this work. This approach ensures that linear dependence among the basis functions and limited machine and data accuracy have a minimal adverse effect on the quality of fit achieved. The problem of bending in the Gummel plots at high current levels and the associated problem of obtaining a suitable linear approximation to find $I_{\mathrm{S}}$ and $N_{\mathrm{F}}$, can be overcome by plotting $\log (\beta)$ against $\log \left(I_{\mathrm{c}}\right)$ [18]. The use of $\log \left(I_{\mathrm{c}}\right)$ as the independent variable corresponds with the use of the intrinsic base-emitter voltage $V_{\mathrm{BE}}{ }^{\prime}$, because the high doping in the base of HBT's eliminates high injection effects. The parameters $I_{\mathrm{SE}}, N_{\mathrm{E}}$, $I_{\mathrm{SES}}$ and $N_{\mathrm{ES}}$ can be obtained using the $\log (\beta) / \log \left(I_{\mathrm{c}}\right)$ characteristics as described in $[10,18]$. Again the SVD least squares algorithm is preferred here to minimise errors. The quality of fit to measured data is shown in Figure 4 and the associated parameters for a typical power HBT are shown in Table 1 (The chi-square test for the fit is typically better than $10^{-3}$ for all diode parameters). It is important to appreciate at this stage that after the initial fit to Gummel data and extraction of parasitic element values (usually determined during microwave calibration), no further fitting is carried out and the measured data 
is compared directly with the predicted simulation results in the remainder of this paper.

The saturation currents $\left(I_{\mathrm{SE}}, I_{\mathrm{SES}}, I_{\mathrm{SC}}, I_{\mathrm{SCS}}, I_{\mathrm{S}}, I_{\mathrm{SR}}\right)$ are assumed to have a simplified temperature dependence of the form [10]:

$$
\ln \left(I_{S}\right)=\frac{-T_{S}}{T}+\ln \left(I_{S \Theta}\right)
$$

where $T$ is the temperature in Kelvin. $T_{\mathrm{S}}$ and $I_{\mathrm{S} 0}$ are constants which define the temperature dependence of the saturation current. The values of $T_{\mathrm{S}}$ and $I_{\mathrm{S} 0}$ are extracted from plots of $\log$ (saturation current) against $1 / T$, by fitting a straight line to measured data. The temperature coefficients of the saturation currents are also be extracted using the SVD least-squares fitting algorithm, when more than two sets of data points are available. In the case of temperature dependent ideality factors, the ideality factor is approximated using a temperature dependence as follows:

$$
N(T)=N_{S}(T=0)[1+\alpha \Delta T]
$$

Here, the ideality factor $N_{\mathrm{S}}$ is referenced to $T=0 \mathrm{~K}$. The temperature coefficient of the saturation current and ideality factors require data taken from at least 3 different die temperatures. This can be obtained from measured data or extracted using thermal simulations of the type described later in this paper.

The current sources in the model represent the four processes of base transport, collection of injected electrons, base-collector avalanche breakdown and base-emitter zener breakdown. The recombination processes in the base are modelled using time-dependent electron collection current sources $i_{\mathrm{CC}}$ and $i_{\mathrm{EE}}$ (Table 1). A fraction $\alpha_{\mathrm{T}}$ of the injected electron current $I_{\mathrm{F}}$ is collected by the collector (the parameter $\alpha_{\mathrm{T}}$ is the base transport factor, which in an ideal device with no recombination would be unity). The model (Table 1) utilizes the forward Early Voltage $V_{\mathrm{AF}}$ and reverse Early Voltage $V_{\mathrm{AR}}$, both of which assume high values in HBTs. Most of the current source parameters are defined on the basis of the transport and physics of the device (see Table 1).

Velocity overshoot can have a significant effect on the transport of carriers in HBTs and plays a significant role in the base-collector space-charge region $[10,12,19]$. An approach similar to that of 
Grossman et al [10] has been adopted here, where the current $i_{\mathrm{CC}}$ in the base-collector space-charge region is calculated using a simplified two-section velocity profile. The two velocities, $v_{\mathrm{OV}}$ and $v_{\mathrm{SAT}}$ correspond to the average velocity in the overshoot region and the average velocity in the saturated region respectively (taken here as $3 \times 10^{5} \mathrm{~ms}^{-1}$ and $1 \times 10^{5} \mathrm{~ms}^{-1} \quad$ respectively for $\mathrm{n}$-type GaAs). The current $i_{\mathrm{EE}}$ is evaluated in a similar manner to $i_{\mathrm{CC}}$.

The bulk ohmic resistances $R_{\mathrm{BExt}}, R_{\mathrm{CEx}}, R_{\text {EExt }}$, vertical contact resistance $R_{\mathrm{Econt}}$, lateral contact resistances $R_{\mathrm{Bcont}}, R_{\text {Ccont}}$, and spreading resistance spreading resistances $R_{\mathrm{BB}}, R_{\mathrm{CC}}$, and the resistance of the undepleted collector region $R_{\text {Cundep, }}$ are defined using the established physical descriptions (see for example $[10,20,21])$. The model is simplified by neglecting the vertical base contact resistance, intrinsic vertical bulk ohmic base resistance, and the intrinsic emitter vertical resistance, which assume very small values in practice compared with the other associated resistances.

The capacitances associated with HBTs have been modelled using well known physical depletion region approximations and space-charge region charge-storage relationships described in [10,20,21], taking full account of the graded heterojunction at the emitter $\left(C_{\mathrm{BE}}\right.$ and $\left.C_{\mathrm{BEs}}\right)$. The base-collector junction in most HBTs is an abrupt homojunction, consisting of the highly doped base and lightly doped collector regions, Figure 4 . The lightly doped collector region interfaces with the highly doped collector contact layer. The base-collector depletion capacitance model represents the two regimes when the base-collector depletion layer is contained within the lightly doped collector and when the depletion layer extends into the highly doped contact layer (as in [10]). This capacitance $C_{\mathrm{BC}}$ is also attributed to both the intrinsic and extrinsic base regions (using the established $X$ dependency). Hole storage in the emitter was assumed to be negligible in HBTs and the associated capacitance was omitted from the model. Charge-storage in the base-emitter space-charge region can be significant at low current levels and empirical relationship of Grossman [10] was used to describe the associated capacitance $C_{\mathrm{BEs}}$.

It is very important to distinguish clearly between the equivalent circuit element values corresponding to variations with DC bias (and varying temperature due to self-heating) and those corresponding to 
changes in the instantaneous values of voltages and currents occurring at a faster rate than the thermal time constant $\tau_{\mathrm{TH}}$ (that is at a constant temperature). The former correspond to the change in small-signal element value as a function of bias and temperature, whereas the latter correspond to the instantaneous large-signal microwave values (where $\mathrm{f}>>1 / 2 \pi \tau_{\mathrm{TH}}$ - that is above $1 \mathrm{MHz}$ for power devices). The latter parameters are evaluated at a constant temperature corresponding to the temperature at the DC bias point.

The simulator described here has been developed to model structures with multiple emitter, base and collector contacts, as depicted in Figure 1, and can handle any configuration. The simulation divides the structure in to a number of basic 'cells' containing usually one or two emitter fingers. Each emitter finger 'cell' is treated as a separate heat source, which determines the local temperature (for the immediately surrounding base-emitter and base-collector structures) and is solved as a separate electrical cell, coupled to the transistor contacts. The parasitic elements $L_{\mathrm{Bpar}}, L_{\mathrm{Cpar}}, L_{\mathrm{Epar}}, R_{\mathrm{Bpar}}, R_{\mathrm{Cpar}}$ and $R_{\mathrm{Epar}}$, in Figure 3, each represent a series inductance and resistance representing the connecting lines (and probe) parasitic elements (and are usually small for power devices). Parasitic capacitances $C_{\mathrm{BEpar}}, C_{\mathrm{BCpar}}$ and $C_{\mathrm{CEpar}}$ model the passive inter-contact capacitances. Capacitances $C_{\mathrm{Bpad}}, C_{\mathrm{Epad}}$ and $C_{\mathrm{Cpad}}$ model the pad capacitances of the base, emitter and collector respectively. The functional form and typical parameter values of the capacitances and resistances in the physics-based model are shown in Table 2.

Self-heating generally has a more pronounced effect in GaAs/AlGaAs HBT's than in silicon BJT's because of the lower thermal conductivity of GaAs. Heat dissipation can be largely attributed to line sources and has a time constant $\tau_{\mathrm{TH}}$, typically in the region of a microsecond. A new model has been developed by the author to model the thermal properties of multi-cell HBTs. Liou et al $[22,23]$ have shown that the variation in temperature between individual cells in HBTs can be significant and will eventually lead to thermal runaway and thermally triggered collapse of the collector current. The collapse of the collector current at high power densities occurs because of the negative temperature coefficient of the collector current and base-emitter voltage at constant base current. Liou's analysis is based on large-scale numerical solution of the thermal problem. This reveals very interesting and useful data, but is too slow for CAD and everyday usage. A thermal equivalent circuit-based approach was described by 
Baureis [24] who developed a multi-cell thermal model based on transforming measured inter-emitter temperature measurements to a thermal equivalent circuit with the interaction between each emitter described by thermal resistances coupling each emitter. In this way each emitter is considered as a thermal source interacting with every other emitter stripe.

The multi-cell thermal analysis in this work is based on new thermal resistance matrix scheme. This can be understood by considering the two forms of thermal equivalent circuit for of a three emitter finger HBT shown in Figure 5. It is possible to analyse a specific design of HBT using the type of equivalent circuit shown in Figure 5(a) (as in [24]), which is easy to interpret, but difficult to associate directly with a generalised characterization technique (this approach is closer to the idea of a thermal conductance matrix) and becomes increasingly topologically complex with increasing numbers of emitter fingers. However, a more generalised and flexible analysis can be based on the model shown in Figure 5(b), which can immediately be associated with the concept of a thermal resistance matrix. This is conceptually slightly harder to visualise at first inspection as the elements do not correspond directly with equivalent circuit resistances of Figure 5(a), but are readily extracted from measured or simulated data, and the model is very easy to expand to devices with large numbers of emitter fingers. In fact, as we will see, the coupled thermal equivalent circuit resistances in Figure 5(a) increase with increasing cell separation, whereas the coupled thermal resistances in the matrix associated with Figure 5(b) decrease in value with increasing separation.

Following the model topology of Figure 5(b), the temperatures of the cells $\boldsymbol{T}$ are related to the power dissipated in each cell $\boldsymbol{P}$ defined by:

$$
\left[\boldsymbol{T}-T_{\odot}\right]=\left[\boldsymbol{R}_{T h}\right][\boldsymbol{P}]
$$

where the power dissipation $P_{\mathrm{i}}$ in each cell $i$ is given by,

$$
P_{i}=V_{C B} \cdot I_{C_{i}}+V_{B E} \cdot I_{E_{i}}
$$

Note that in the multi-cell model the emitter and collector currents are all a function of the individual cells and the thermal interaction with associated cells. The thermal resistance matrix $\left[\mathbf{R}_{\mathbf{t h}}\right]$ is defined as in Figure 5(b), by the matrix: 


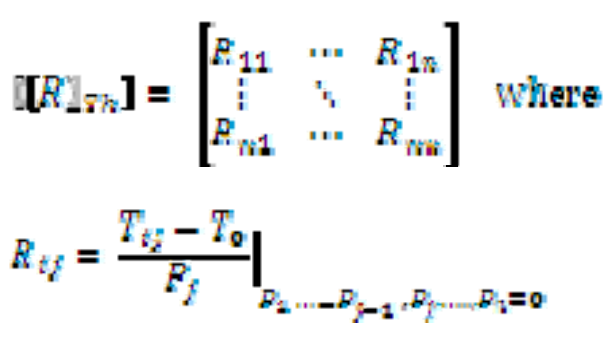

Note that for the matrix entry $i, j \quad R_{\mathrm{Th} \mathrm{i}, \mathrm{j}}=R_{\mathrm{Th} \mathrm{j}, \mathrm{i}} \quad$ (ie $R_{\mathrm{Th} 12}=R_{\mathrm{Th} 21}, R_{\mathrm{Th} 13}=R_{\mathrm{Th} 31}$ etc). $P_{1}, P_{2} \ldots$ are the power dissipations in each respective finger. This leads to a matrix with some elements of symmetry. Also at low temperatures and as an initial estimate at low-moderate current densities $\mathrm{R}_{\mathrm{Th33}}=\mathrm{R}_{\mathrm{Th} 11}$ (with similar symmetry for larger numbers of emitter fingers). However, it is important to appreciate that the whole matrix must be developed during the analysis because at high power densities it is possible for any one of the cells to experience thermal runaway (in which case $\mathrm{R}_{\mathrm{Th3} 3} \neq \mathrm{R}_{\mathrm{Th} 11}$ etc). The thermal resistance matrix must be evaluated at each simulation point where the bias has changed as the thermal resistance element values $R_{\mathrm{THij}}$ are a function of temperature. In this work it is assumed that the temperature of the device is a function of the large-signal operating DC voltages and currents at the transistor terminals, as the microwave signal varies at a rate far higher than the thermal time constant.

In practice the self-induced thermal resistance $R_{\text {Thii }}$ is usually close to the thermal resistance of an isolated single cell. The magnitude of the coupled thermal resistance $R_{\text {Thij }}$ depends on the design of the transistor and in particular the separation. If the separation between cells is large then $R_{\text {Thij }}$ tends to zero and if the separation is very small its value tends to $R_{\text {Thii. }}$. Hence, the coupled thermal resistance between distant cells is significantly smaller than the coupled thermal resistance of adjacent cells. In practice, the interaction between adjacent cells overwhelms the influence of other cells. Hence, errors in determining coefficients other than those of closely coupled cells have only minimal impact of the model.

The thermal resistances at a given average die temperature can be determined for test structures where individual emitter fingers are electrically isolated from adjacent fingers. The finger $n$ is biased at an appropriate level, dissipating power $P_{\mathrm{n}}$, and the temperatures of all the other unbiased fingers $x$ are measured. In this way the thermal resistance matrix is calculated using $R_{\mathrm{nn}}=\left(T_{\mathrm{n}}-T_{0}\right) / P_{\mathrm{n}}$ and $R_{\mathrm{xn}}=$ 
$\left(T_{\mathrm{x}}-T_{0}\right) / P_{\mathrm{n}}$ where $\quad P_{0} \ldots P_{\mathrm{n}-1}, P_{\mathrm{n}+1} . . P_{\mathrm{N}}=0$. This process is repeated $N / 2$ times for an $N$ finger transistor (symmetry), requiring $N / 2$ test structures with electrically isolated fingers and can be carried out experimentally, using fabricated test structures (for example as part of process monitor area of the wafer) or by utilizing a three-dimensional thermal analysis simulator.

A three-dimensional thermal analysis simulation, HeatWave, was written to calculate the thermal resistance matrix using the highly efficient technique described in $[22,23,25]$. The heat flow equation $\nabla . \kappa(T) \nabla T=0$ is solved for a three-dimensional temperature distribution using the method of Liou [22] and Gao et al [25], utilizing the Kirchhoff transform for temperature dependent conductivity, to yield the temperature distribution close to the surface (in the active region of the transistor). This method uses a double Fourier expansion method to speed up the solution. The heatsink is assumed to be attached to the bottom of the substrate (at $T=T_{\text {mount }}$ ), whilst all other surfaces except the heat sources (region below the emitter fingers) are assumed to be adiabatic. The model accounts for the heat-shunt effect of an airbridge. The test structures with isolated emitter stripes, described above, are simulated for the actual die size, for a given die mounting temperature. The matrix for a power HBT with 16 emitter fingers requires 16 separate thermal simulations, but can typically be extracted in 30 minutes on a personal computer, yielding a typical accuracy of better than 5\% (when compared with results obtained from infrared measurement). A typical thermal resistance matrix for an eight finger HBT (with emitter fingers grouped two per cell) obtained using this approach is shown in Table 3. This approach avoids the need to perform an experimental temperature characterization of each design. The same simulator has been used to validate the thermal aspects of the electro-thermal model by comparing the temperature distribution of the full simulated device with measured infrared data. A typical surface temperature distribution for an eight cell device with two closely spaced emitter fingers per cell (16 emitter fingers in total) is shown in Figure 6. Note that it is not possible to distinguish the temperature of individual emitter fingers in each cell because of their close proximity, although there is significant variation in temperature between cells (simulated at $V_{\mathrm{CE}}=4 \mathrm{~V} I_{\mathrm{C}}=0.25 \mathrm{~A}$, below current collapse or thermal runaway). The $3 \mathrm{D}$ simulator HeatWave utilized over 13,300 mesh points on the surface of the device to obtain these results, achieving very good agreement with measured IR data, shown in Figure 7 (note that the IR measurements have a 
resolution of $\left.1.7^{\circ} \mathrm{C}\right)$.

The electro-thermal utilizes the thermal resistance matrix in conjunction with equations (4) and (5) to calculate the distributed temperatures, which are then used in self-consistent fashion with the physics-based electrical model to determine the instantaneous terminal currents and voltages. The thermal time constant $\tau_{\mathrm{TH}}$ of the device is simulated using a simplified combination $R_{\mathrm{TH}} C_{\mathrm{TH}}$ where $R_{T H}$ is the net thermal resistance of the device. In this work the thermal time constant was measured for sample dies, for a given average die temperature (typical values were found to lie in the range 0.1 to $50 \mu \mathrm{s}$ ). The thermal resistance (and the thermal resistance matrix element values) is a function of temperature and is approximated using,

$$
R_{T H}=R_{T H}(30 \odot)+\frac{d R_{T H}}{d T} \cdot(T-30 \odot)
$$

The rate of change of the thermal resistance with temperature was taken as $5 \mathrm{~W}^{-1}$ in this work.

\section{Numerical Solution}

The HBT non-linear equivalent circuit model is analysed using a non-linear nodal analysis routine, solving each emitter 'cell' simultaneously. The nodal analysis proceeds by establishing the microwave equivalent circuit matrices such that,

$$
Y V=I
$$

where $\boldsymbol{Y}$ is the nodal admittance matrix, $\boldsymbol{V}$ and $\boldsymbol{I}$ are the nodal voltage and current vectors (DC or time-dependent) respectively. The current matrix $\quad \boldsymbol{I}$ contains both linear and non-linear sources. In the case of a solution scheme where the thermal model is not simultaneously solved directly with the electrical model, the matrices are re-arranged into the form,

$$
\boldsymbol{F}=\boldsymbol{Y} \boldsymbol{V}-\boldsymbol{I} \quad \text { solving for } \boldsymbol{F}=0
$$

A modified Newton scheme was implemented to solve the nodal matrices using the scheme,

$$
\boldsymbol{F}^{\prime} \delta \boldsymbol{V}=\ldots
$$


where $\mathbf{F}^{\prime}$ is the Jacobian (with entries $F^{\prime}{ }_{\mathrm{i}, \mathrm{j}}=\partial F_{\mathrm{i}} / \partial V_{j}$ ) and $\boldsymbol{\delta} \mathbf{V}$ is the vector of values $\delta V_{\mathrm{j}}=V_{\mathrm{j}}^{\text {new }}-V_{\mathrm{j}}$ old . Here,

$$
F^{\prime}=Y-I^{\prime}
$$

Here the admittance matrix has been linearized. The implementation of this scheme results in an iterative scheme where each matrix is re-evaluated each iteration; the non-linear admittance matrix elements being updated using values obtained with the most recent nodal voltage values. The updated nodal voltages are obtained using,

$$
\boldsymbol{V}^{\text {new }}=\boldsymbol{V}^{\text {old }}+\gamma \delta \boldsymbol{V}
$$

Note that a relaxation factor $\gamma$ multiplies the vector $\boldsymbol{\delta} \mathbf{V}$ in this scheme. This is essential to ensure convergence using the linearized admittance matrix in this non-linear scheme. An adaptive system is used to select the optimum value of $\gamma$, based on the rate of convergence and the requirement, $F^{\text {new }}{ }_{-}<$ $F^{\text {old }}$. The use of modified Newton schemes is discussed in detail in [26]. A particularly effective algorithm for selecting the relaxation factor $\gamma$ was developed during this work and takes the form:

$$
\gamma=\left(\frac{1}{1+V_{\max } \xi_{\max }}\right) \mid
$$

where $V_{\max }$ is the maximum of the nodal voltages at that iteration and $\xi_{\max }$ is the maximum error at that iteration $\left(\delta V_{\max }\right)$. This algorithm allows stable convergence rates of up to 100 times faster than when using conventional means of determining the relaxation parameter [26].

This solution scheme involves the development of several large and complex matrices. The extraction of the Jacobian is particularly involved because of the inter-dependency of the current sources on several of the nodal voltages. However, once the scheme was coded it has proven to be robust and normally requires between 4 and 30 iterations to achieve convergence to $0.1 \mu \mathrm{V}$ at every node in the model (ie: typically $\left.10^{-5} \%\right)$.

The full electro-thermal model can be solved for the system: 


$$
\begin{aligned}
& {\left[\begin{array}{ll}
\frac{\partial F_{2}}{\partial V} & \frac{\partial F_{2}}{\partial T} \\
\frac{\partial F_{2}}{\partial V} & \frac{\partial F_{2}}{\partial T}
\end{array}\right]\left[\begin{array}{l}
\partial V \\
\partial T
\end{array}\right]=\left[\begin{array}{l}
-F_{1} \\
-F_{2}
\end{array}\right]} \\
& \text { where } F_{1}=Y V-1 \\
& \qquad F_{2}=R_{T H} P_{\text {diss }}-\Delta T
\end{aligned}
$$

This system of equations is solved for $\boldsymbol{V}$ and $\boldsymbol{T}$ using an adaptive relaxation factor similar to (13). In practice the efficiency and convergence properties were found to be improved by solving the temperature dependence and thermal equations as a separate iterative loop (containing the above electrical solution) rather than performing a full non-linear matrix solution. This approach is particularly expedient since the temperature solution is well behaved over most of the operating region of the device and convergence of the outer temperature loop occurs normally within 2 to 3 iterations (except during thermal runaway or current collapse when it may require up to 10 iterations).

\section{DC Simulation Results}

The simulation has been used to model a variety of $\mathrm{AlGaAs} / \mathrm{GaAs}$ and $\mathrm{InGaAs} / \mathrm{InP}$ HBTs. Transistors consisting of 2, 8 and 16 emitter fingers and finally multi-cell devices with repeating sets of 16 fingers have been investigated. These larger power devices are of particular interest from the perspective of validating the model for large-signal purposes. Figure 7 compares the measured and simulated results for DC characteristics of a $16 \times 3 \times 20 \mu \mathrm{m} \mathrm{AlGaAs} / \mathrm{GaAs} \mathrm{HBT}$, for base currents in the range 0,3 to $1.5 \mathrm{~mA}$ at $\mathrm{T}_{\text {mount }}=45^{\circ} \mathrm{C}$. A current gain of 53 was obtained at $I_{\mathrm{B}}=1.5 \mathrm{~mA}$ and $V_{\mathrm{CE}}=4 \mathrm{~V}$. The simulation has been used to investigate current collapse at high power densities, arising from the non-uniform temperature distribution in the HBT.

\section{Small-Signal Equivalent Circuit Model and $S$ Parameters}

A small-signal equivalent circuit model is established by replacing the ideal diodes in the large-signal model with incremental resistances based on determining the small-signal incremental resistance of the diode at the bias-point,

$$
r_{\text {diode }}=\frac{\partial V_{\text {diode }}}{\partial I_{\text {diode }}}=\left.\frac{N k T}{q I_{s}} \exp \left(\frac{-q V_{\text {diode }}}{N k T}\right)\right|_{V_{\text {diode }}}
$$


This leads to a small-signal circuit model of the form shown in Figure 8, which can be evaluated in the frequency domain. The resistances and capacitances of this model are obtained from the physical bias-dependent relationships. Steady-state small-signal CW operation is assumed in this model and the time-independent thermal model is utilized here.

The S parameters of an HBT are calculated using the bias-dependent small-signal equivalent circuit model. A DC simulation is performed to calculate the temperature of the device and establish the DC currents and voltages for the model. The bias-dependent element values are calculated to provide the data for the small-signal equivalent circuit model. The equivalent circuit model is analysed to extract the nodal admittance matrix using a generalised algorithm. The admittance matrix is calculated at each frequency and then reduced to a $2 \times 2$ matrix using a pivotal condensation technique. The two-port admittance matrix is then converted in to a two-port $S$ parameter matrix. This approach leads to a faster solution for small-signal parameters than the alternative time-domain simulation with the large-signal model.

It should be noted that the $S$ parameters are a function of bias-point and ambient temperature. The comparison of a typical set of measured and simulated $S$ parameter data is shown in Figure 9 for $I_{\mathrm{C}}=$ $40 \mathrm{~mA}$ and $V_{\mathrm{CE}}=3 \mathrm{~V}$. The transistors were measured using coplanar on-wafer probes with a HP8510C network analyzer, calibrated using LRM and an impedance standard substrate. It is also possible using this model to extract S parameters over the entire DC operating range for a constant given ambient temperature and requires only a matter of seconds on a workstation. This scenario corresponds to data extracted using pulse-S-parameter methods and could be utilized in conjunction with other large-signal design methods.

\section{Large-Signal Simulation}

Large-signal simulation is performed using a harmonic-balance scheme, which allows the harmonic performance of Class A, AB and B HBT amplifiers to be assessed. Steady-state CW operation is 
assumed, utilizing the time-independent thermal model in conjunction with the large-signal model of Figure 3. The harmonic-balance scheme is based on a secant-solver algorithm, which is computationally more efficient than traditional Jacobian schemes for small workstations and personal computers. The input and output load reflection coefficients are specified and the bias point is chosen by the user for a given die-mounting temperature. The simulator then performs a DC simulation to establish the initial bias and thermal conditions under small-signal conditions. This is followed by a number of simulations at varying power levels, starting at small signal conditions, where the power level at the input is steadily increased in steps until power saturation occurs at the output. The DC bias and temperature distribution are re-evaluated at each new increasing input signal level, modifying the DC nodal voltages, microwave performance and the temperature as the transistor operates in an increasingly non-linear fashion. The harmonic-balance scheme tests for convergence by checking the time-domain voltage waveforms at the input and output for convergence over a number of iterations and testing for the RMS error (with a minimum of $10 \mu \mathrm{V}$ accuracy normally available). This is carried out in conjunction with a test for convergence in the input and output reflection coefficients to within an error of 0.02 .

The large-signal performance of a $16 \times 3 \times 20 \mu \mathrm{m}$ emitter AlGaAs/GaAs HBT operating at $900 \mathrm{MHz}$ as a Class $\mathrm{AB}$ amplifier is shown in Figure 10 (tuned for maximum output power), with simulated and measured data $I_{\mathrm{C}}=40 \mathrm{~mA}, V_{\mathrm{CE}}=4.2 \mathrm{~V}, T_{\text {mount }}=60^{\circ} \mathrm{C}$. When $T_{\text {mount }}$ was varied from $40^{\circ} \mathrm{C}$ to $90^{\circ} \mathrm{C}$ the small-signal gain decreased by $1.5 \mathrm{~dB}$ and the $P_{1 \mathrm{~dB}}$ decreased by $1.8 \mathrm{dBm}$ (measured and simulated data tracked closely). The load-pull characteristics for a larger $32 \times 3 \times 20 \mu \mathrm{m}$ emitter device are shown in Figure 11, illustrating the output power and power-added efficiency at the $1 \mathrm{~dB}$ compression point $I_{\mathrm{C}}=$ $35 \mathrm{~mA}, V_{\mathrm{CE}}=4.2 \mathrm{~V}, T_{\text {mount }}=50^{\circ} \mathrm{C}$. The agreement between measured and simulated data is good, with deviations in the region of $1 \mathrm{~dB}$ and $5 \%$ PAE over the range of impedance investigated.

\section{Modelling Parameter Spreads}

Physical and physics-based models allow device and circuit parameter spreads due to variations in processing and wafer growth to be evaluated. The model described here has been used to investigate the impact of variation in the thickness and doping levels of the emitter, base and collector layers of the 
device. Figure 12 shows the variation in amplifier gain for a $0.5 \mathrm{~W} 900 \mathrm{MHz} \mathrm{HBT}$ amplifier design as a function of base layer thickness. It is interesting to note that for an expected layer thickness of $0.1 \mu \mathrm{m}$, the corresponding measured gain was $21.4 \mathrm{~dB}$ for the specified load and source reflection coefficients (at a mounting temperature of $40^{\circ} \mathrm{C}$ ). The model predicts a gain of $21.1 \mathrm{~dB}$ for this base thickness, with a spread in gain of $2 \mathrm{~dB}$ as the thickness was varied from 0.05 to 0.2 microns. This model allows designers to rapidly evaluate the spread in microwave and DC parameters as a function of geometry and layer specification, and is thus particularly suited to process-oriented design.

\section{Conclusions}

A comprehensive electro-thermal model has been described which incorporates a physics-based equivalent circuit model and a new multi-finger thermal model. A thermal resistance matrix method has been described which allows the rapid evaluation of the temperature distribution across the emitter fingers. The model has been validated for a variety of power HBT structures and has demonstrated good agreement for DC, small- and large-signal operation over a variety of operating conditions and die temperatures. This model is well suited to process-oriented CAD.

\section{Acknowledgements}

The author is grateful to M/A-COM Inc. (An AMP Company) and to Dave Wu, Yong-Hoon Yun, Greg Henderson of the Corporate Research and Development Center for their support and interest in this work and to Paul McIntosh, Ke Lu and Michael Staniforth at Leeds for valuable discussions and experimental data..

\section{References}

[1] M. Salib, F. Ali, A. Gupta and D. Dawson, "A 1 Watt, 8-14 GHz HBT Amplifier with $>45 \%$ Peak Power Added Efficiency", IEEE Microwave and Guided Wave Letters, Vol. 2, No. 11, pp. 447-448, November 1992

[2] H. Wang, K.-W. Chang, D.C-W Lo, L.T. Tran, J.C. Cowles, T.R. Block, G.S. Dow, A. Oki, A.Oki, D.C. Streit, and B.R. Allen, "A 62 GHz Monolithic InP-Based HBT VCO", IEEE Microwave and Guided Wave Letters, Vol. 5, No. 11 pp. 388-390, November 1995 
[3] Y.I. Ryu, K.W. Kobayashi and A.K. Oki, "A Monolithic Broadband Doubly Balanced EHF HBT Star Mixer with Novel Microstrip Baluns", Proc. IEEE MTT-S, Orlando, Fl., pp.119-122, May 1995

[4] D.J. Holder, "Characterisation and Modelling of Heterostructure Bipolar Junction Transistors", PhD Thesis, University of Leeds, 1991

[5] L.L. Liou, J.L. Ebel, and C.I. Huang, "Thermal Effects on the Characteristics of $\mathrm{AlGaAs} / \mathrm{GaAs}$ Heterojunction Bipolar Transistors Using Two Dimensional Numerical Simulation", IEEE Trans. Electron Devices, ED-40, No. 1, pp. 35-43, January 1993

[6] S.A. Maas, B.L. Nelson and D.L. Tait, "Intermodulation in Heterojunction Bipolar Transistors", IEEE Trans. MTT, Vol. 40, No. 3, pp. 442-447, March 1992

[7] M.Y. Frankel and D. Pavlidis, "An Analysis of the Large-Signal Characteristics of AlGaAs/GaAs Heterojunction Bipolar Transistors", IEEE Trans. MTT, Vol.40, No.3, pp.465-474, March 1992

[8] K. Lu, P.A.Perry, T.J. Brazil, "A New Large-Signal AlGaAs/GaAs HBT Model Including Self-Heating Effects with Corresponding Parameter Extraction Procedure", IEEE Trans. MTT, MTT-43, Np. 7, pp. 1433-1445, July 1995

[9] D-W Wu, M. Fukuda and Y-H Yun, "A Novel Extraction Method for Accurate Determination of HBT Large-Signal Model Parameters", Proc. IEEE-MTT-S, Orlando, Florida, pp.1235-1238, 1995

[10] P.C. Grossman and J. Choma Jr., "Large-signal modeling of HBT's Including Self-Heating and Transit Time Effects", IEEE Trans. Microwave Theory and Techniques, Vol. 40, No.3, pp.449-464, March 1992

[11] D.A. Teeter, J.R. East, R.K. Mains and G.I. Haddad, "Large-Signal Numerical and Analytical HBT Models", IEEE Trans. Electron Devices, Vol. 40, No.5, pp. 837-845, May 1993

[12] M.E. Hafizi, C.R. Crowell and M. Grupen, "The DC Characteristics of GaAs/AlGaAs Heterojunction Bipolar Transistors with Application to Device Modelling", IEEE Trans. Electron Devices, Vol. 37, No.10, pp.2121-2129, 1990

[13] G. Stringfellow, "Effect of surface treatment on recombination velocity and diode leakage current in GaP", J. Vac. Sci. tech., Vol. 13, No.4, pp.908-913, Jul-August 1978

[14] C. Sandroff, R. Nottenburg, J. Bischoff and R. Bhat, "Dramatic enhancement in the gain of GaAs/AlGaAs heterostructure bipolar transistors by surface chemical passivation", Appl. Phys. Lett., Vol. 51, No.1, pp.33-35, July 6, 1987

[15] J.J.X. Feng, D.L. Pulfrey, J. Sitch and R. Surridge, "A Physics-Based HBT SPICE Model for Large-Signal Applications", IEEE Trans. Electron Devices, ED-42, No. 1, pp. 8-14, January 1995 
[16] D.K. Schroder, Semiconductor Material and Device Characterization, Wiley-InterScience, New York, 1990

[17] W.H. Press, B.P. Flannery, S.A. Teukolsky and W.T. Vetterling, Numerical Recipes - The Art of Scientific Computing, Cambridge Press, 1988

[18] P.C. Grossman and A. Oki, "A Large-Signal DC Model for GaAs $/ \mathrm{Ga}_{1-\mathrm{x}} \mathrm{Al} \mathrm{x}_{\mathrm{x}} \mathrm{As}$ heterojunction Bipolar Transistors", Bipolar Circuits and Technology Meeting, pp.258-262, September, 1989

[19] S. Tiwari, "HBT Device Physics", Proc. IEEE GaAs IC Symposium, Short Course on HBT-IC Technology and Applications, 1992.

[20] A.S. Grove, Physics and Technology of Semiconductor Devices, New York, Wiley, 1967

[21] P. Antognettic and G. Massobrio (Eds), Semiconductor Device Modeling with SPICE, McGraw-Hill, New York, 1988

[22] L.L. Liou, J.L. Ebel and C.I. Huang, "Thermal Effects on the Characteristics of AlGaAs/GaAs Heterojunction Bipolar Transistors Using Two-Dimensional Numerical Simulation", IEEE Trans. Electron Devices, ED-40, No. 1, pp.35-42, January 1993

[23] L.L. Liou and B. Bayraktaroglu, "Thermal Stability Analysis of AlGaAs/GaAs Heterojunction Bipolar Transistors With Multiple Emitter Fingers", IEEE Trans. Electron Devices, ED-41, No.5, pp. 629-635, May 1994

[24] P. Baureis, "Electrothermal Modeling of Multi-Emitter Heterojunction-Bipolar Transistors (HBTs)", Proc. INMMC-94, Duisburg, Germany, pp.145-148, Oct.1994

[25] G-B Gao, M-Z Whang, X Gui and H. Morkoç, "Thermal Design Studies of High-Power Heterojunction Bipolar Transistors", IEEE Trans. Electron Devices, ED-36, No.5, pp.854-863, May 1989

[26] S. Selberherr, Analysis and Simulation of Semiconductor Devices, Springer Verlag, Vienna, 1984 


\section{Captions:}

Table 1 Functional forms and typical parameter values for diodes and current sources for the physics-based model of a $16 \times 3 \times 20$ micron (16 emitter finger) transistor.

Table 2 Functional forms and typical parameter values for capacitances and resistances for the physics-based model of a $16 \times 3 \times 20$ micron ( 16 emitter finger) transistor.

Table 3 Thermal resistance matrix for an eight finger $8 \times 3 \times 20$ micron AlGaAs/GaAs HBT, (emitter fingers are grouped on cells of two fingers), calculated using the HeatWave three-dimensional thermal simulator.

Figure 1 Schematic view of a typical multi-cell power HBT chip structure with detail crosssection of one-cell containing two emitter fingers (data from the cross-section forms the basis of the physics-based description).

Figure 2 Multi-cell electro-thermal models for a HBT, illustrating coupling of cells and self-consistent Solution of (i) electrical and thermal equivalent circuit models inside each cell and (ii) entire device. Each cell corresponds to a section of the transistor associated with a single emitter finger ( 4 cells illustrated here). The notation $\mathrm{v}^{*}{ }_{\mathrm{BE}}$ and $\mathrm{v}^{*}{ }_{\mathrm{CE}}$ indicate the voltages across the terminals of each cell.

Figure 3 Physics-based DC and large-Signal equivalent circuit model of one cell of the HBT model.

Figure 4 Forward and reverse Gummel Plots for an AlGaAs/GaAs HBT showing measured and fitted data (SVD algorithms and a six diode model were used to obtain a high quality fit).

Figure 5 Multi-cell thermal equivalent circuits of a 3 emitter finger HBT (a) conventional model (b) model based on thermal resistance matrix method.

Figure 6 Temperature distribution on the surface of a 16 finger $(16 \times 3 \times 20$ micron emitter $)$ HBT, with emitter fingers group in sub-sets of 2. (a) HBT layout showing schematic position of emitter fingers (b) contour plot of surface temperature of full chip device $(0.4 \times 0.5$ $\mathrm{mm}$ ), contours are spaced $4^{\circ} \mathrm{C}$ apart with a die mounting temperature $T_{\text {mount }}$ of $70^{\circ} \mathrm{C}$ (c) temperature profile at section AA across the HBT comparing simulated data with infra-red measured data (resolution of IR measured data is $1.7^{\circ} \mathrm{C}$ ).

Figure 7 Simulated and measured DC characteristics of a $16 \times 3 \times 20$ micron emitter HBT, showing DC and pulsed $I / V$ characteristics $\left(T_{\text {mount }}\right.$ of $\left.50^{\circ} \mathrm{C}\right)$.

Figure 8 Physics-based small-signal equivalent circuit model of HBT (active region). 
Figure $9 \mathrm{~S}$ parameters of $16 \times 3 \times 20$ micron emitter $\mathrm{AlGaAs} / \mathrm{GaAs} \mathrm{HBT}\left(V_{\mathrm{CE}}=3 \mathrm{~V}, I_{\mathrm{C}}=40 \mathrm{~mA}\right.$, $T_{\text {mount }}$ $\left.=40^{\circ} \mathrm{C}\right),------$ simulated, ___ measured data.

Figure 10 Simulated and measured power transfer characteristics of $16 \times 3 \times 20$ micron emitter $\mathrm{AlGaAs} / \mathrm{GaAs}$ chip HBT $\left(V_{\mathrm{CE}}=4.2 \mathrm{~V}, I_{\mathrm{C}}=40 \mathrm{~mA}, T_{\text {mount }}=60^{\circ} \mathrm{C}\right)$, operating in Class $\mathrm{AB}$ mode at $900 \mathrm{MHz}$, tuned for maximum power with $\Gamma_{\text {source }}=0.75 \angle-175^{\circ}, \quad \Gamma_{\text {load }}=0.5$ $\angle 55^{\circ}$.

Figure 11 (a) Simulated, (b) measured load-pull characteristics, (c) simulated and (d) measured power added efficiency characteristics as a function of impedance (at $1 \mathrm{~dB}$ compression point $)$ of $32 \times 3 \times 20$ micron emitter AlGaAs $/$ GaAs HBT chip $\left(V_{\mathrm{CE}}=4.2 \mathrm{~V}, I_{\mathrm{C}}=35 \mathrm{~mA}, T_{\text {mount }}\right.$ $=50^{\circ} \mathrm{C}$ ), operating in Class $\mathrm{AB}$ mode at $1.88 \mathrm{GHz}, \Gamma_{\text {source }}=0.8 \angle-175^{\circ}$.

Figure 12 Variation of amplifier gain as a function of base layer thickness for a $0.5 \mathrm{~W}$ power amplifier utilizing a $16 \times 3 \times 20$ micron emitter $\mathrm{AlGaAs} / \mathrm{GaAs}$ chip $\mathrm{HBT}\left(V_{\mathrm{CE}}=4.2 \mathrm{~V}\right.$, $I_{\mathrm{C}}=40 \mathrm{~mA}, T_{\text {mount }}=40^{\circ} \mathrm{C}$ ), at $900 \mathrm{MHz}$, with $\Gamma_{\text {source }}=0.75 \angle-175^{\circ}, \quad \Gamma_{\text {load }}=0.5 \angle$ $155^{\circ}$. 

Table 1

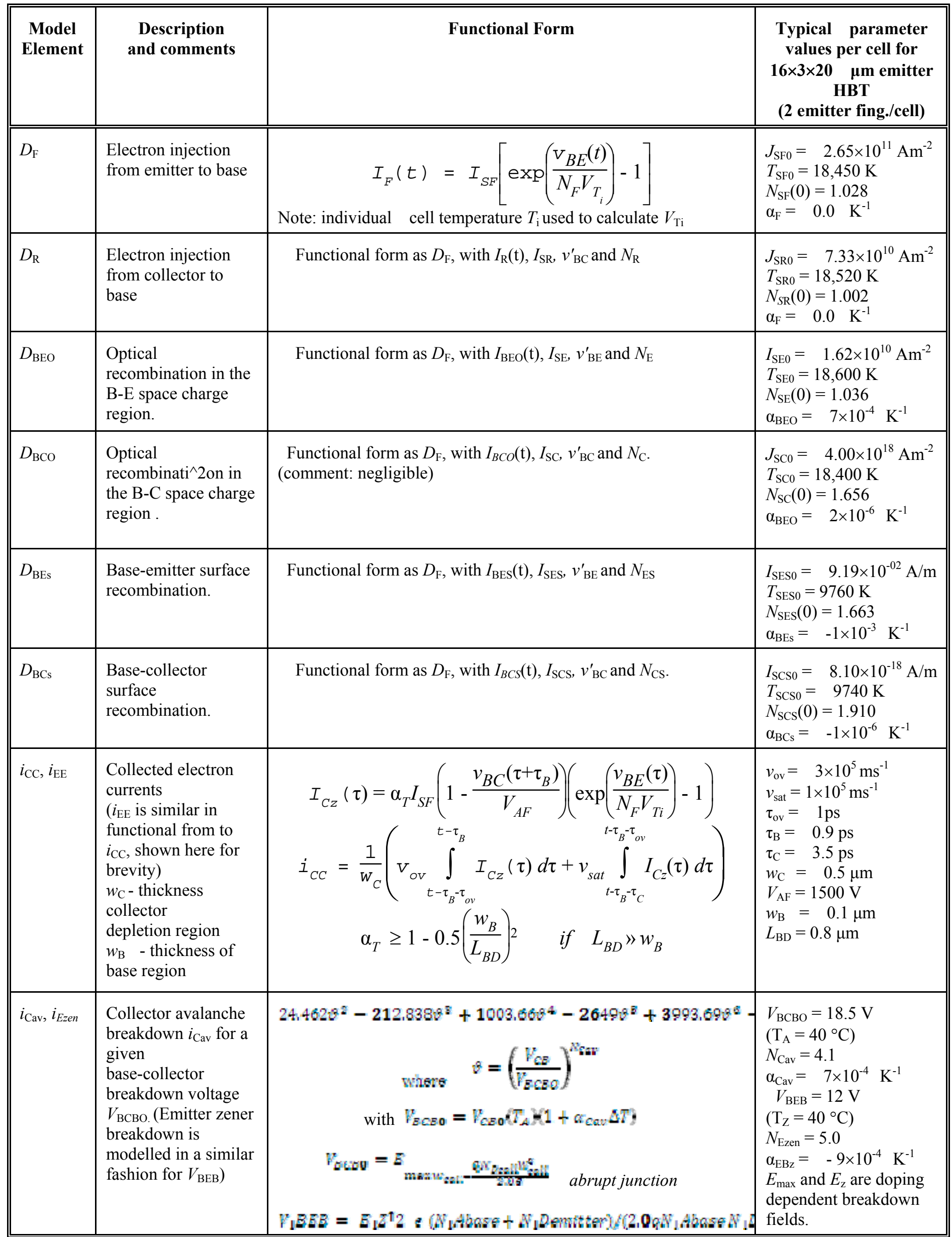


Table 2

\begin{tabular}{|c|c|c|c|}
\hline $\begin{array}{l}\text { Model } \\
\text { Element }\end{array}$ & $\begin{array}{l}\text { Description and } \\
\text { Comments }\end{array}$ & Functional Form & $\begin{array}{l}\text { Typical parameter values } \\
\text { per cell for } 16 \times 3 \times 20 \quad \mu \mathrm{m} \\
\text { emitter } \mathrm{HBT} \\
(2 \text { emitter fingers } / \text { cell })\end{array}$ \\
\hline$C_{\mathrm{BC}}, C_{\mathrm{BE}}$ & $\begin{array}{l}\text { Base-collector and } \\
\text { base-emitter } \\
\text { depletion } \\
\text { capacitances (both } \\
\text { have similar } \\
\text { functional forms - } \\
C_{\mathrm{BC}} \text { is shown here } \\
\text { for brevity) } \\
\text { Forward bias } \\
\text { modelled using } \\
\text { SPICE model [21]. }\end{array}$ & $\begin{array}{c}v_{B C}<0 \quad C_{B C} \geq\left(\left(\frac{C_{J C}}{\left(\left(1+\frac{v_{B C}}{V_{J C}}\right) M_{C}\right.}\right) N_{C}+C_{B C \min }^{N_{C}}\right) \frac{1}{N_{C}} \\
C_{J C}=A_{C} \sqrt{q \varepsilon N_{\text {Dcoll }} N_{\text {Abase }} /\left(2 V_{J C}\left(N_{\text {Abase }}+N_{\text {Dcoll }}\right)\right)} \\
V_{J C}=\frac{k T}{q} \ln \left(N_{\text {Abase }} N_{\text {Dcoll }} / n_{i}^{2}\right)+\delta E_{\text {Ccoll }}\end{array}$ & $\begin{array}{l}N_{\mathrm{C}}=6 \\
M_{\mathrm{C}}=0.5 \\
M_{\mathrm{E}}=0.52 \\
(M \approx 0.33 \text { for lin. graded jn's }) \\
V_{\mathrm{JC}}=1.4 \mathrm{~V}, V_{\mathrm{JE}}=1.6 \mathrm{~V} \\
A_{\mathrm{C}}=\text { area of } \mathrm{B}-\mathrm{C} \text { junc. } \\
X=0.25 \\
\mathrm{n}_{\mathrm{i}}=\text { intrinsic carrier density } \\
\delta \mathrm{E}_{\text {Ccoll }}=\text { collector conduction } \\
\text { band discontinuity } \\
\mathrm{N}_{\text {Abase }}, \mathrm{N}_{\text {Dcolll }} \text { base and intrinsic } \\
\text { collector doping }\end{array}$ \\
\hline$C_{\mathrm{BEs}}$ & $\begin{array}{l}\text { Charge storage in } \\
\text { base-emitter SCR. }\end{array}$ & $C_{E B S}=0.5 C_{B E S 0}\left(1+\tanh \left(\frac{k_{E B S}\left(v_{E E}-F_{B E} F_{I E}\right.}{V_{J E}}\right)\right)$ & $\begin{array}{l}C_{\mathrm{BEs} 0}=8 \mathrm{fF} \\
F_{\mathrm{E}}=0.75 \\
k_{\mathrm{BEs}}=18\end{array}$ \\
\hline$C_{\mathrm{BCH}}$ & $\begin{array}{l}\text { Diffusion } \\
\text { capacitance } \\
\text { (usually negligible) }\end{array}$ & $\begin{array}{c}C_{B C H}=\frac{\tau_{C H}}{N_{B C H} V_{T i}} I_{S B C H}\left(\exp \left(\frac{v_{B C}}{N_{B C H} V_{T i}}\right)-1\right) \\
\text { (assumes a constant lifetime, } I_{\mathrm{BCH}} \text { models hole inj. into base) }\end{array}$ & $\tau_{\mathrm{BCH}}=1 \mathrm{~ns}$ \\
\hline $\begin{array}{l}R_{\text {Bcont }}, \\
R_{\text {Ccont }}, \\
R_{\text {Econt }}\end{array}$ & $\begin{array}{l}\text { Lateral contact } \\
\text { resistances. } \\
\text { NB: } L \text { is the contact } \\
\text { length (in the plane } \\
\text { of the cross-section } \\
\text { in Fig. } 1), W \text { is the } \\
\text { width. }\end{array}$ & $\begin{array}{c}R_{\text {cont }}=\frac{\sqrt{\frac{R_{S}}{G_{C}}}}{W \tanh \left(\frac{L}{L_{C}}\right)} \quad L_{C} \equiv \sqrt{\frac{1}{G_{C} R_{S}}} \\
R_{\mathrm{S}} \text { sheet resistance of layer, } G_{\mathrm{C}} \text { contact conduct./ unit area. }\end{array}$ & $\begin{array}{l}R_{\text {Bcont }}=3.54 \Omega \\
R_{\text {Ccont, }}=0.82 \Omega \\
R_{\text {Econt }}=0.83 \Omega \\
W=20 \mu \mathrm{m} \\
L=3 \mu \mathrm{m} \\
2 \text { fingers per cell }\end{array}$ \\
\hline $\begin{array}{l}R_{\text {BExt, }}, R_{\text {CExt }} \\
R_{\text {Exxt }} \\
R_{\text {Cundep }}\end{array}$ & $\begin{array}{l}\text { Bulk ohmic } \\
\text { resistances. } \\
\text { (again } L \text { is length } \\
\text { and } W \text { width). }\end{array}$ & 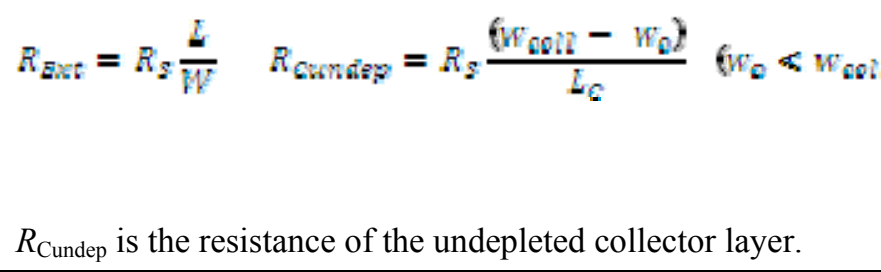 & $\begin{array}{l}R_{\mathrm{BExt}}=1.56 \Omega \\
R_{\mathrm{CExt}}=0.69 \Omega \\
R_{E \mathrm{Ext}}=0.66 \Omega \\
R_{\text {Cundep }}=0 \text { to } 3.4 \Omega \quad \text { (per cell) }\end{array}$ \\
\hline$R_{\text {Econt }}$ & $\begin{array}{l}\text { Vertical emitter } \\
\text { contact resistance }\end{array}$ & $\begin{array}{l}\qquad R_{\text {cont }}=\frac{1}{A_{\text {cont }} G_{C}} \\
A_{\text {cont is contact area }} \\
\text { (metallization) }\end{array}$ & $\begin{array}{l}R_{\text {Econt }}=1.67 \Omega \\
2 \text { fingers per cell }\end{array}$ \\
\hline $\begin{array}{l}R_{\mathrm{BB}} \\
R_{\mathrm{CC}}\end{array}$ & $\begin{array}{l}\text { Base and collector } \\
\text { spreading } \\
\text { resistances. } \\
\text { (equation is similar } \\
\text { for both resistances) }\end{array}$ & $\begin{array}{c}R_{\text {spread }}=\frac{R_{S} L}{K_{\text {geom }} W} \\
K_{\text {geom }}=3 \text { for current enetering from one side (single contact) } \\
K_{\text {geom }}=12 \text { for current entering from two sides (two contacts) }\end{array}$ & $\begin{array}{l}R_{\mathrm{BB}}=1.76 \Omega \\
R_{\mathrm{CC}}=1.04 \Omega \\
\text { (values per cell) }\end{array}$ \\
\hline $\begin{array}{l}L_{\mathrm{Bpar}}, R_{\mathrm{Bpar}} \\
L_{\mathrm{Cpar}}, R_{\mathrm{Cpar}} \\
L_{\mathrm{Epar}}, R_{\mathrm{Cpar}}\end{array}$ & $\begin{array}{l}\text { Terminal parasitic } \\
\text { inductance and } \\
\text { resistance }\end{array}$ & & $\begin{array}{l}L_{\mathrm{Bpar}}=110 \mathrm{pH}, R_{\mathrm{Bpar}}=0.05 \Omega \\
L_{\mathrm{Cpar}}=100 \mathrm{pH}, R_{\mathrm{Cpar}}=0.03 \Omega \\
L_{\mathrm{Epar}}=70 \mathrm{pH}, \quad R_{\mathrm{Epar}}=0.01\end{array}$ \\
\hline
\end{tabular}




\begin{tabular}{|c|c|c|c|}
\hline & & & $\bar{\Omega}$ \\
\hline $\begin{array}{l}C_{\text {BEpar }} \\
C_{\text {BCpar }} \\
C_{\text {CEpar }}\end{array}$ & $\begin{array}{l}\text { Inter-electrode } \\
\text { parasitic } \\
\text { capacitances }\end{array}$ & & $\begin{array}{l}C_{\text {BEpar }}=190 \mathrm{fF} \\
C_{\text {BCpar }}=90 \mathrm{fF} \\
C_{\text {CEpar }}=180 \mathrm{fF}\end{array}$ \\
\hline $\begin{array}{l}C_{\text {Bpad }} \\
C_{\text {Cpad }} \\
C_{\text {Epad }}\end{array}$ & Pad capacitances & $\begin{array}{c}C_{\text {pad }}=\frac{\varepsilon A_{\text {pad }}}{S_{\text {substrate }}} \\
S_{\text {substrate }} \text { is substrate thickness, } A_{\text {pad }} \text { pad area, } \varepsilon \text { permittivity. }\end{array}$ & $\begin{array}{l}C_{\mathrm{Bpad}}=27 \mathrm{fF} \\
C_{\mathrm{Cpad}}=29 \mathrm{fF} \\
C_{\mathrm{Epad}}=23 \mathrm{fF}\end{array}$ \\
\hline
\end{tabular}



Table 3

\begin{tabular}{|c|c|c|c|c|c|c|c|}
\hline 803.7 & 257.9 & 47.2 & 39.4 & 17.0 & 15.1 & 8.1 & 6.6 \\
\hline 257.9 & 803.4 & 63.8 & 47.1 & 21.0 & 17.0 & 8.9 & 8.1 \\
\hline 47.2 & 63.8 & 802.8 & 257.8 & 46.9 & 39.3 & 17.0 & 15.1 \\
\hline 39.4 & 47.1 & 257.8 & 802.5 & 63.7 & 46.9 & 20.7 & 17.0 \\
\hline 17.0 & 21.0 & 46.9 & 63.7 & 802.5 & 257.8 & 47.1 & 39.4 \\
\hline 15.1 & 17.0 & 39.3 & 46.9 & 257.8 & 802.8 & 63.8 & 47.2 \\
\hline 8.1 & 8.9 & 17.0 & 20.7 & 46.9 & 63.8 & 803.4 & 257.9 \\
\hline 6.6 & 8.1 & 15.1 & 17.0 & 39.4 & 47.2 & 257.9 & 803.7 \\
\hline
\end{tabular}


Figure 1
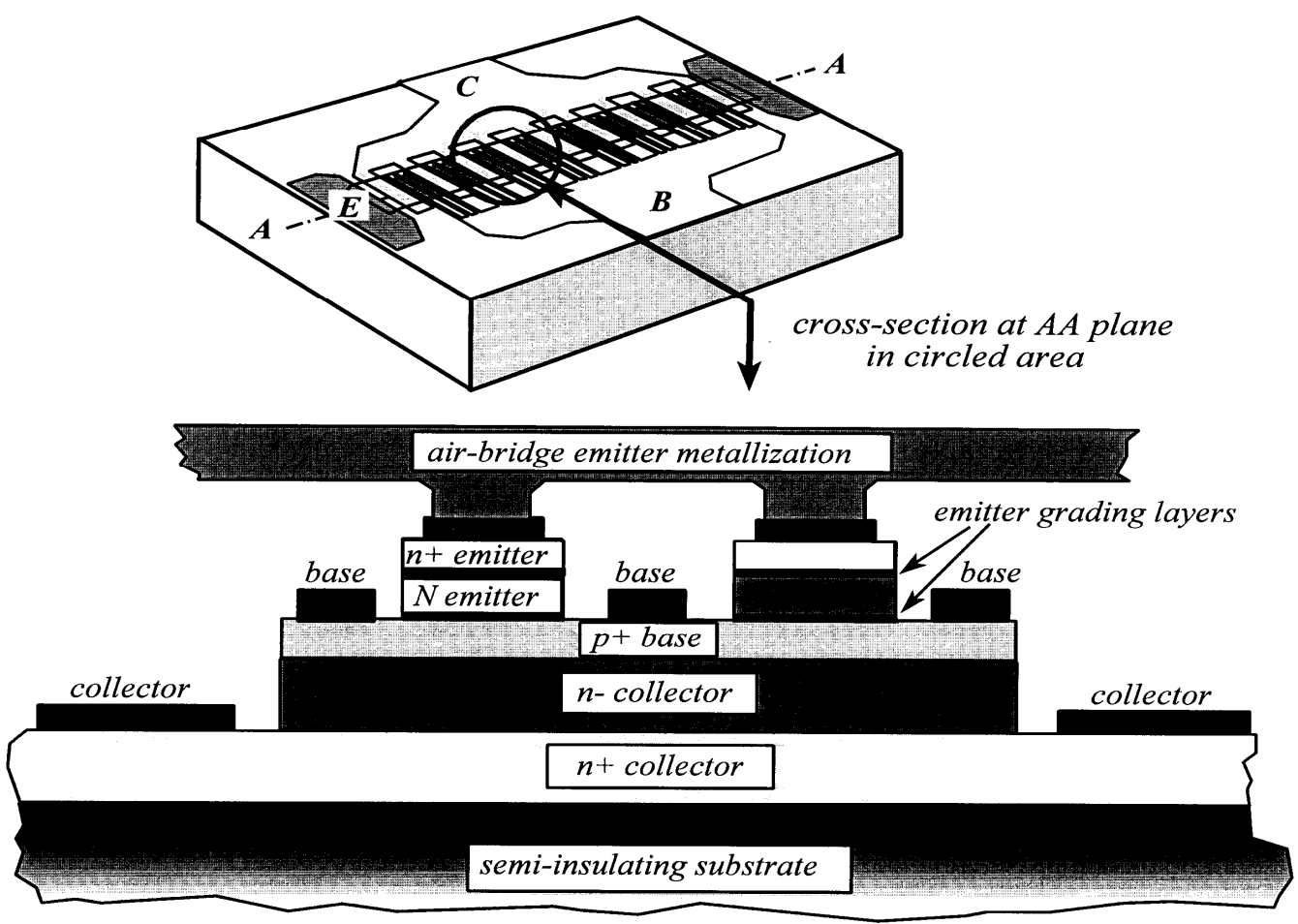
Figure 2

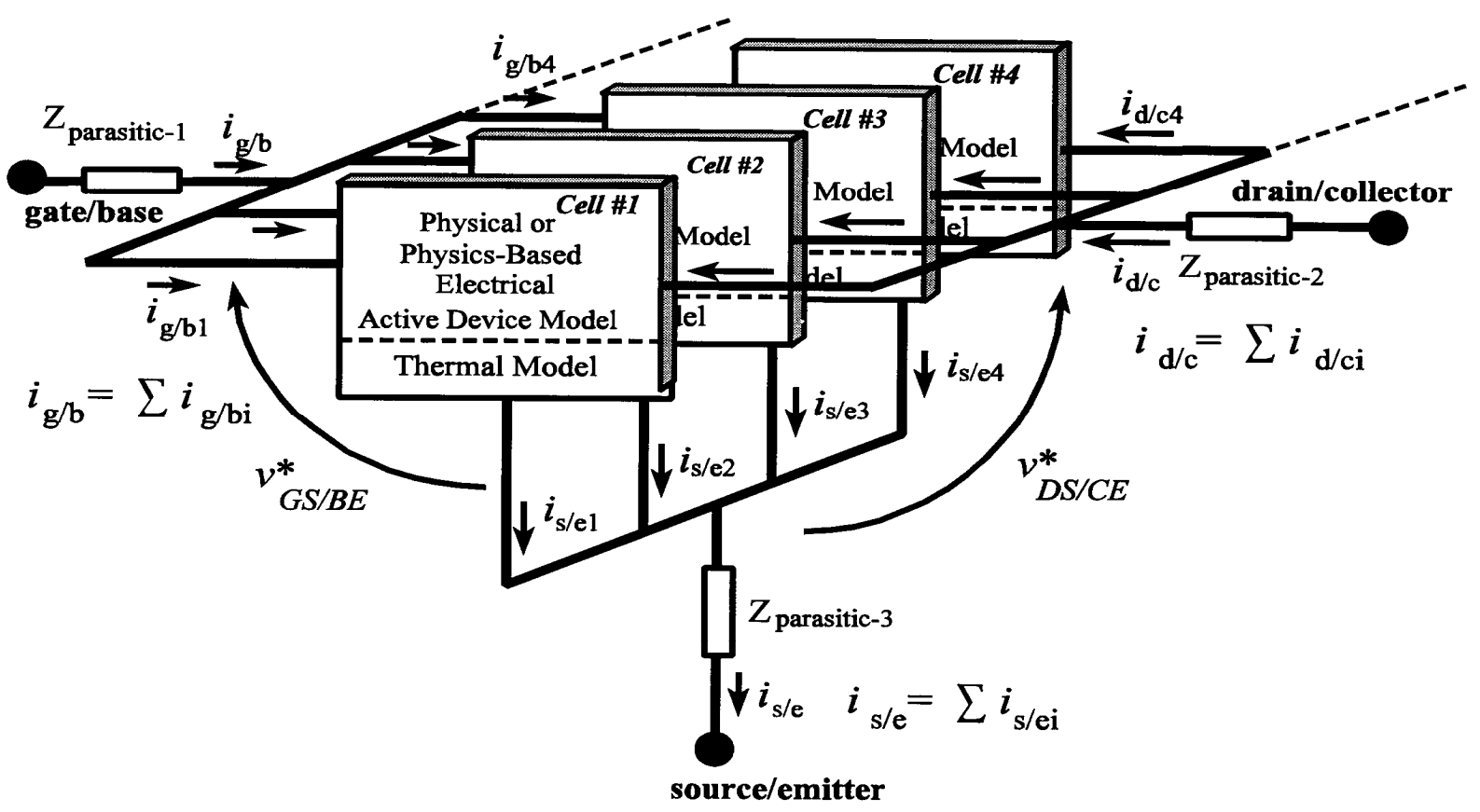


Figure 3

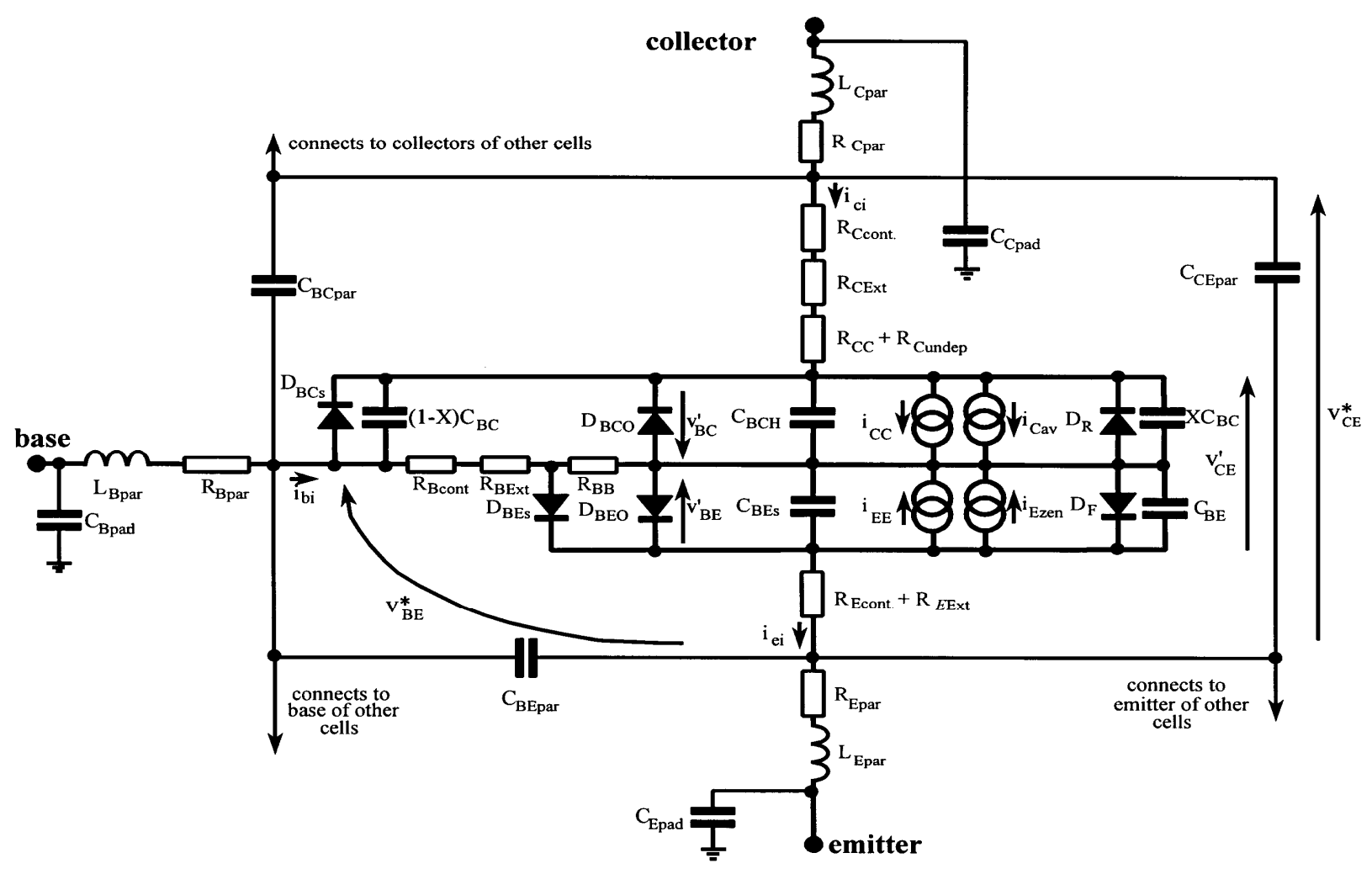


Figure 4

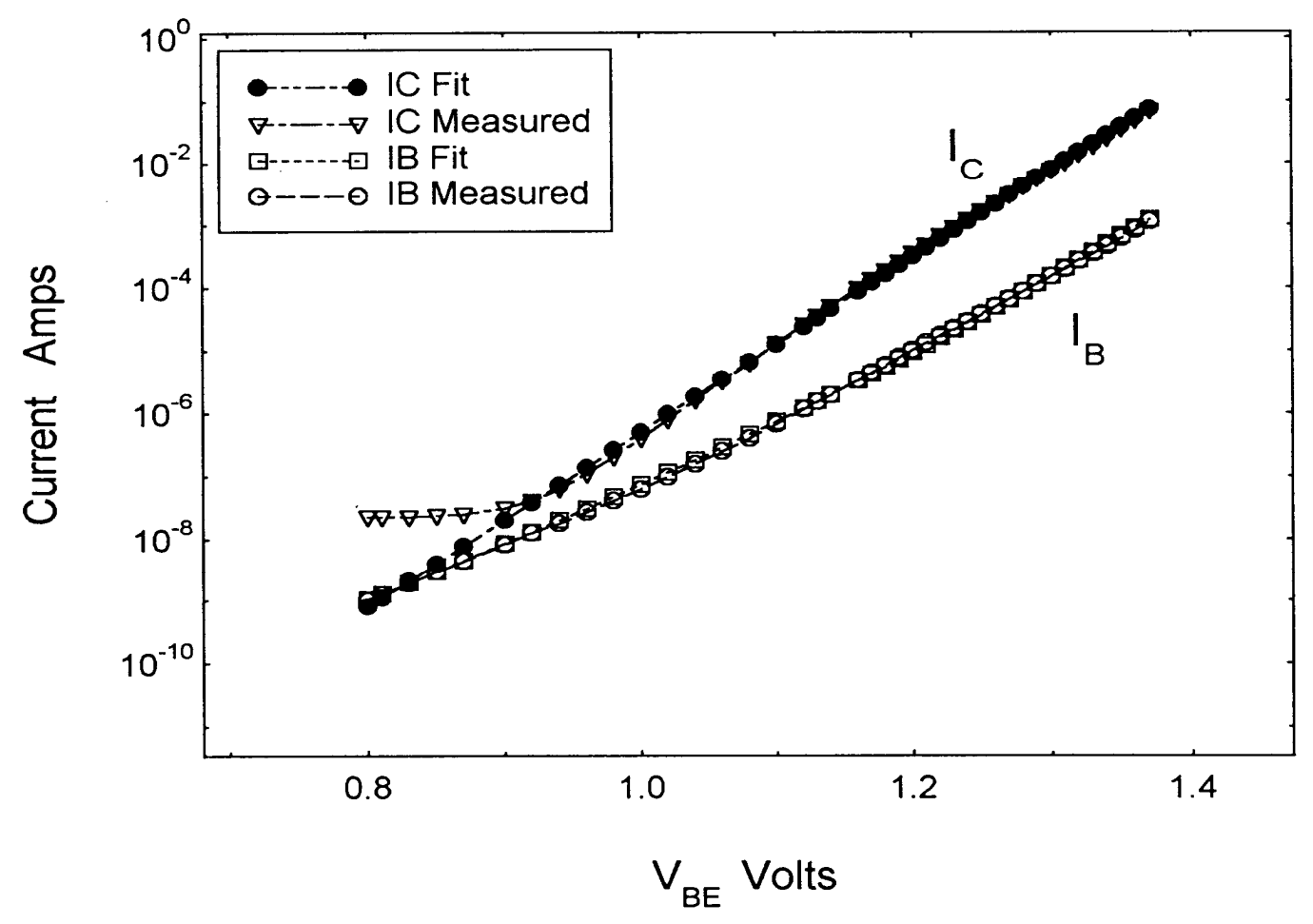


Figure 5.

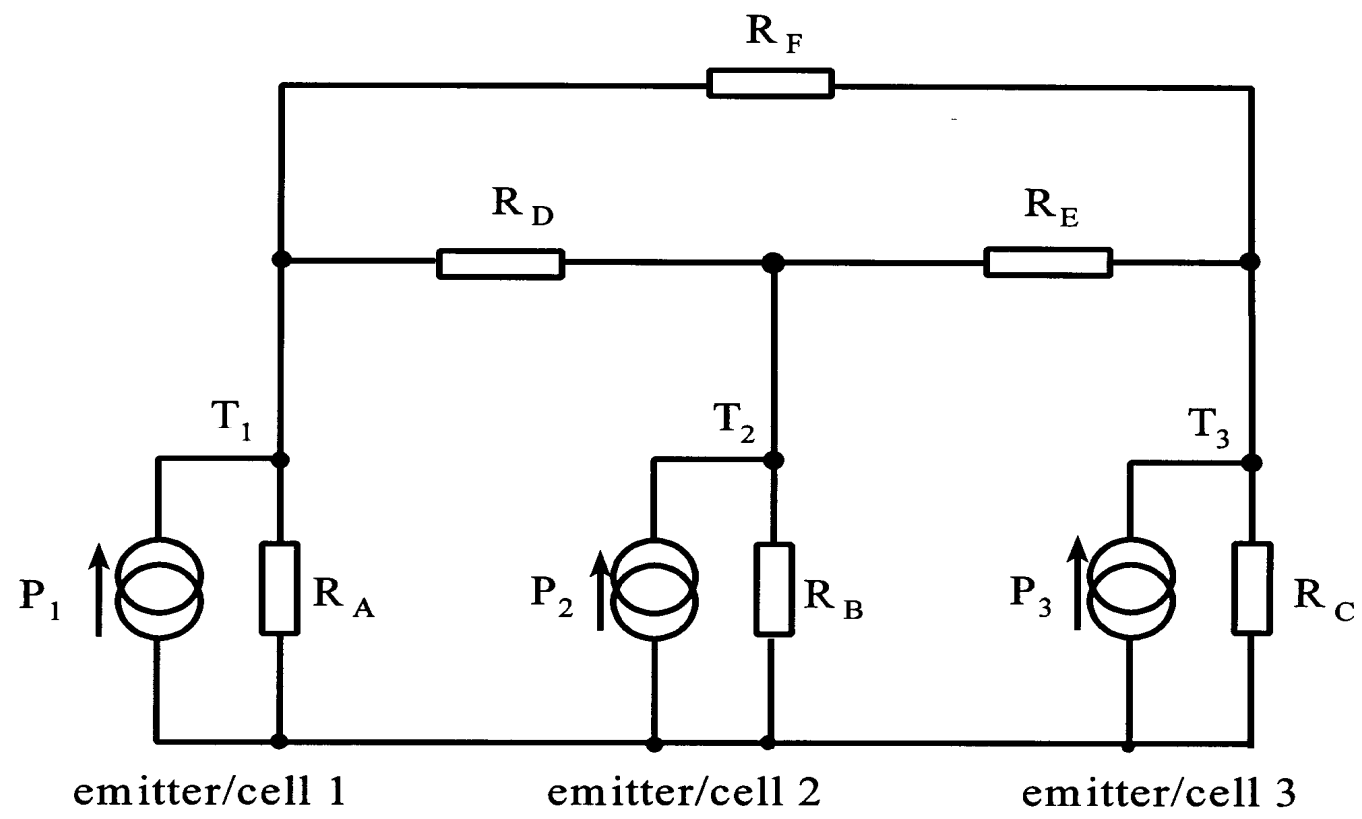

(a)

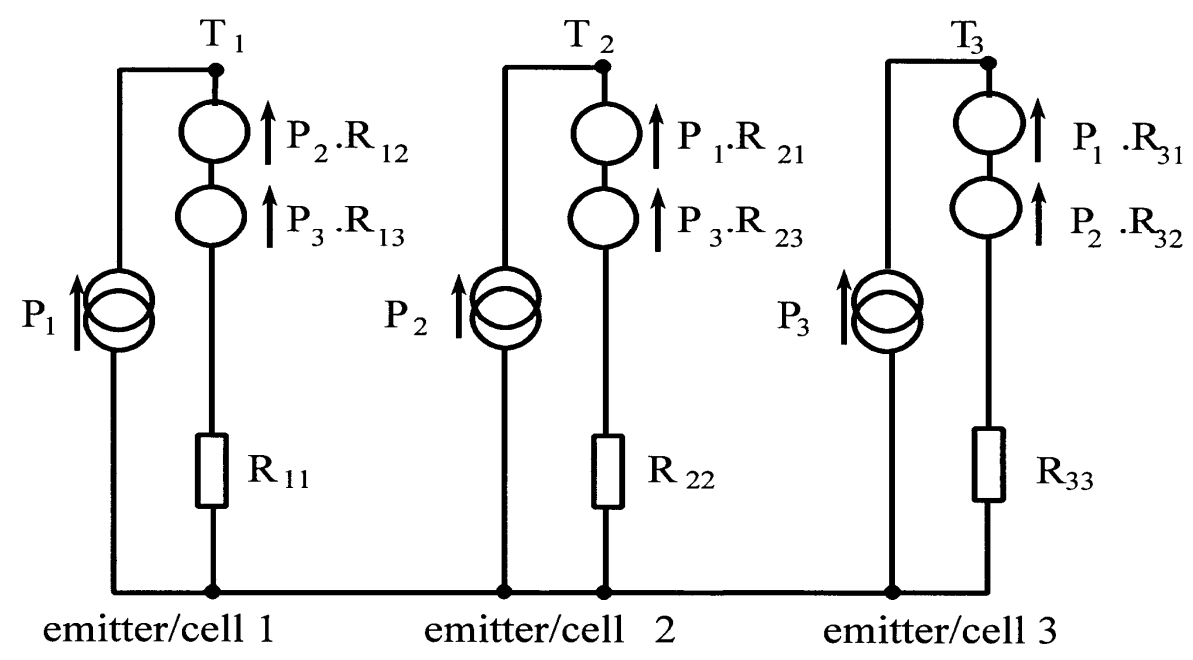

(b) 
Figure 6

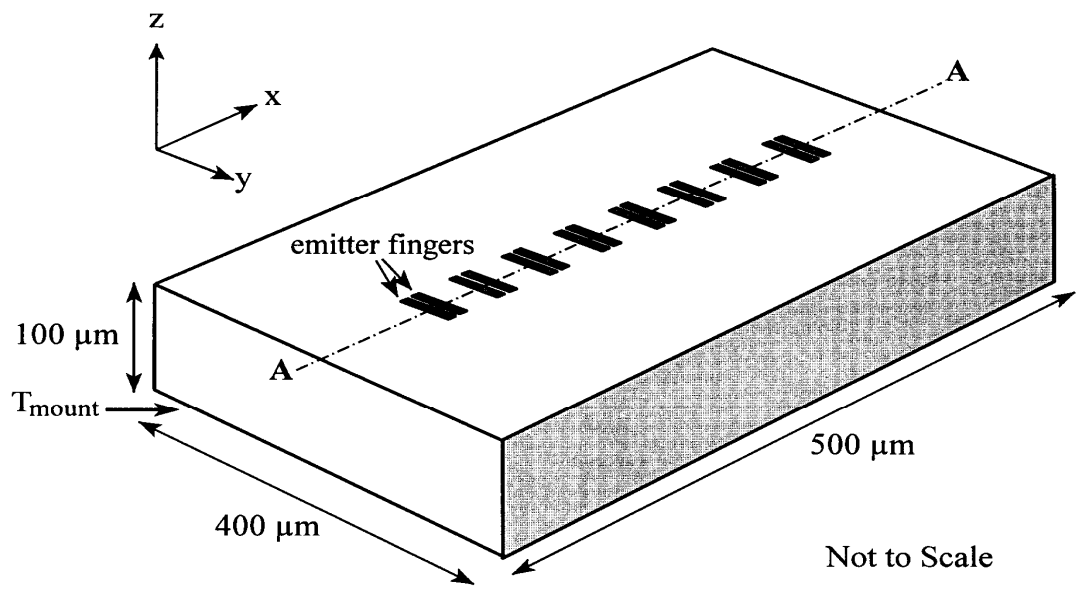

(a)

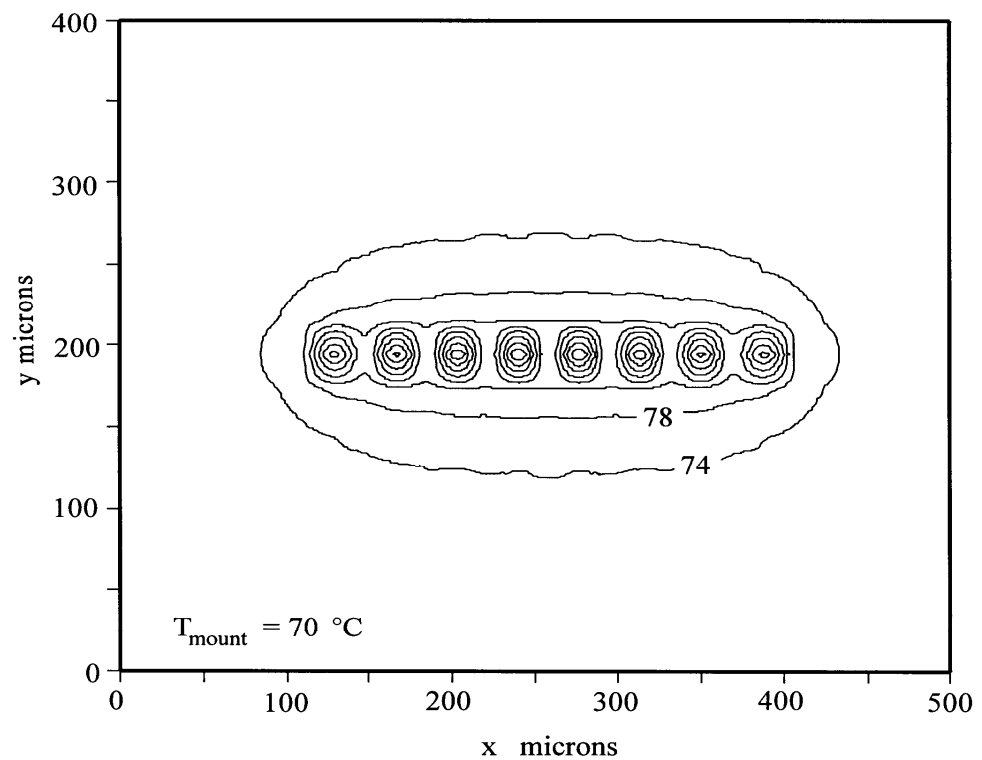

(b)

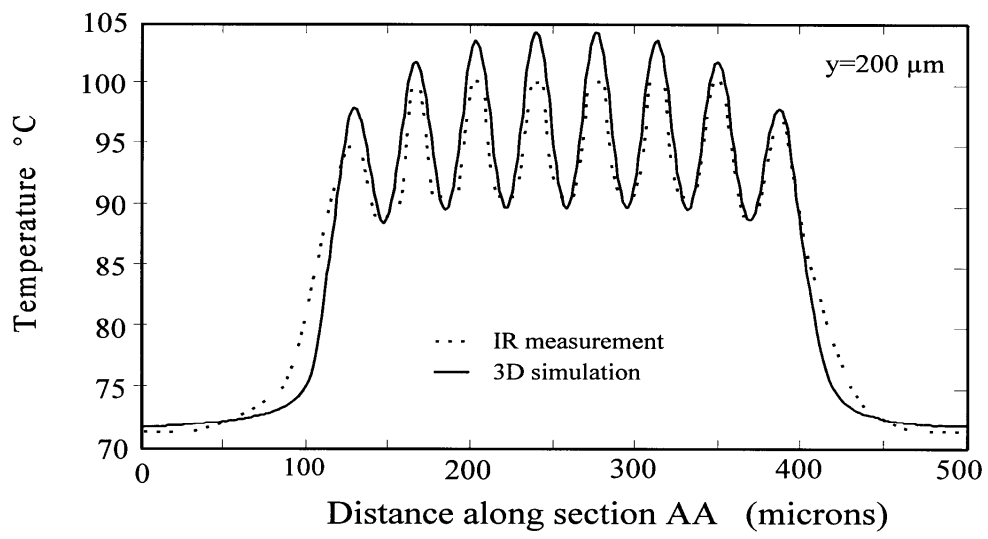

(c) 
Figure 7

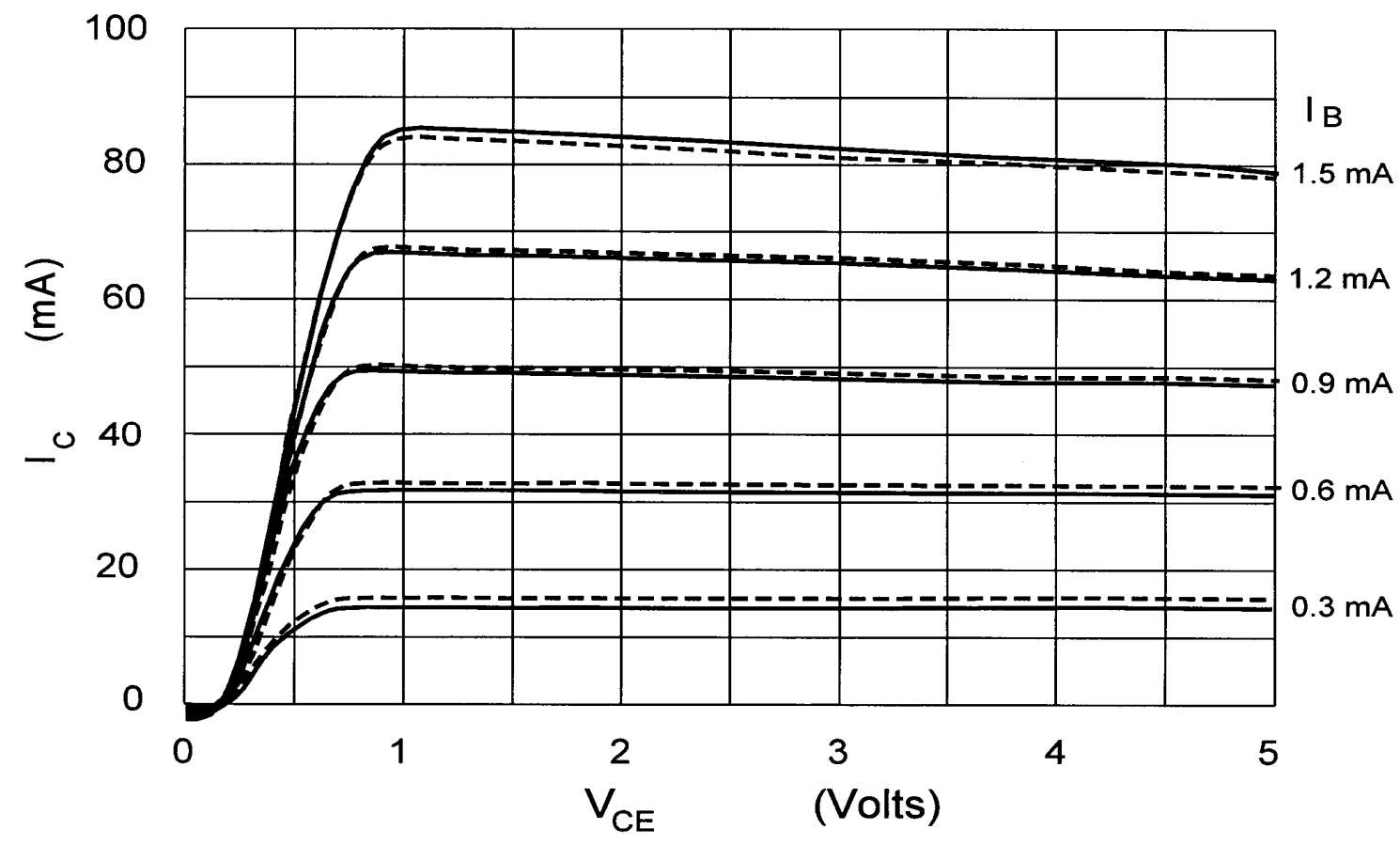


Figure 8

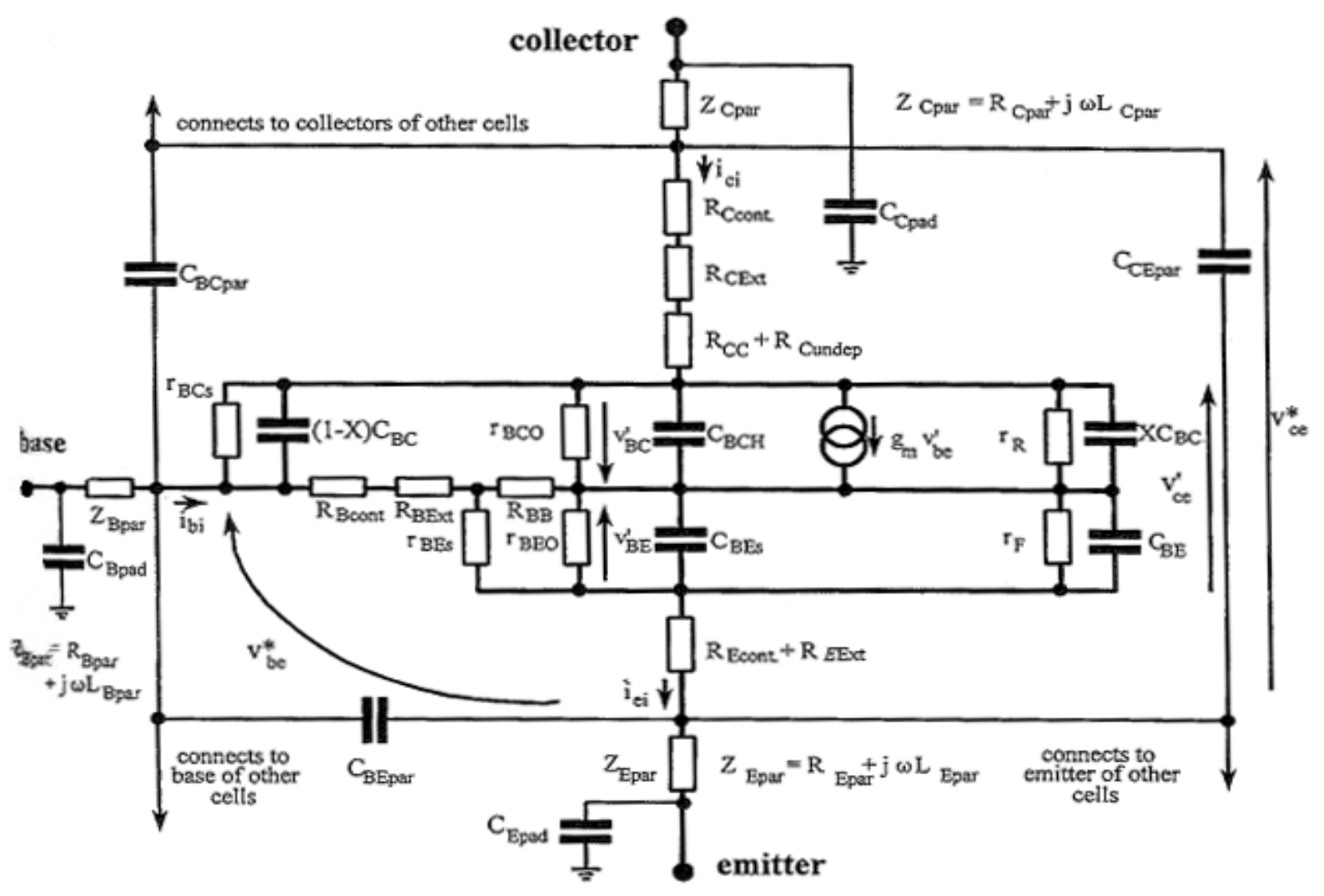


Figure 9

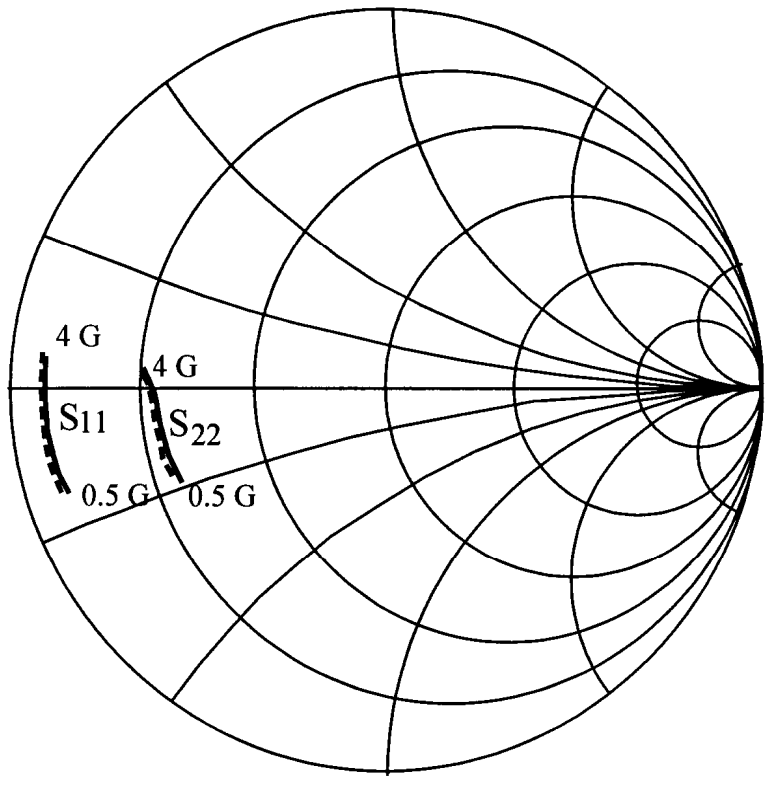

(a)

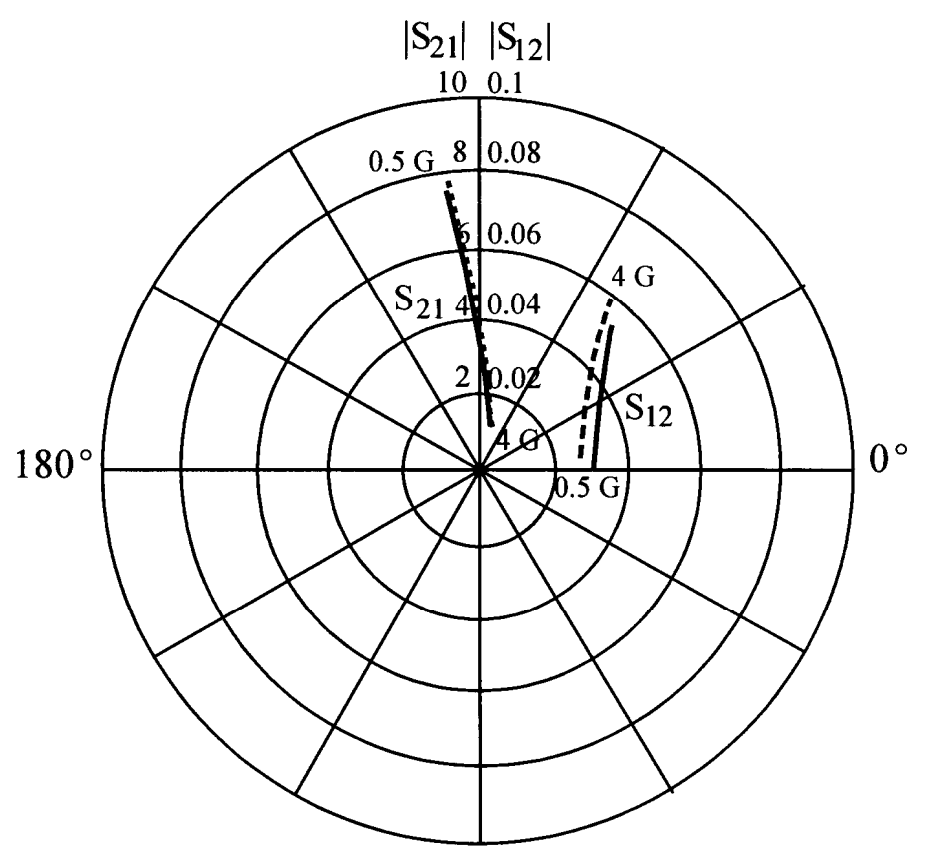

(b) 
Figure 10.

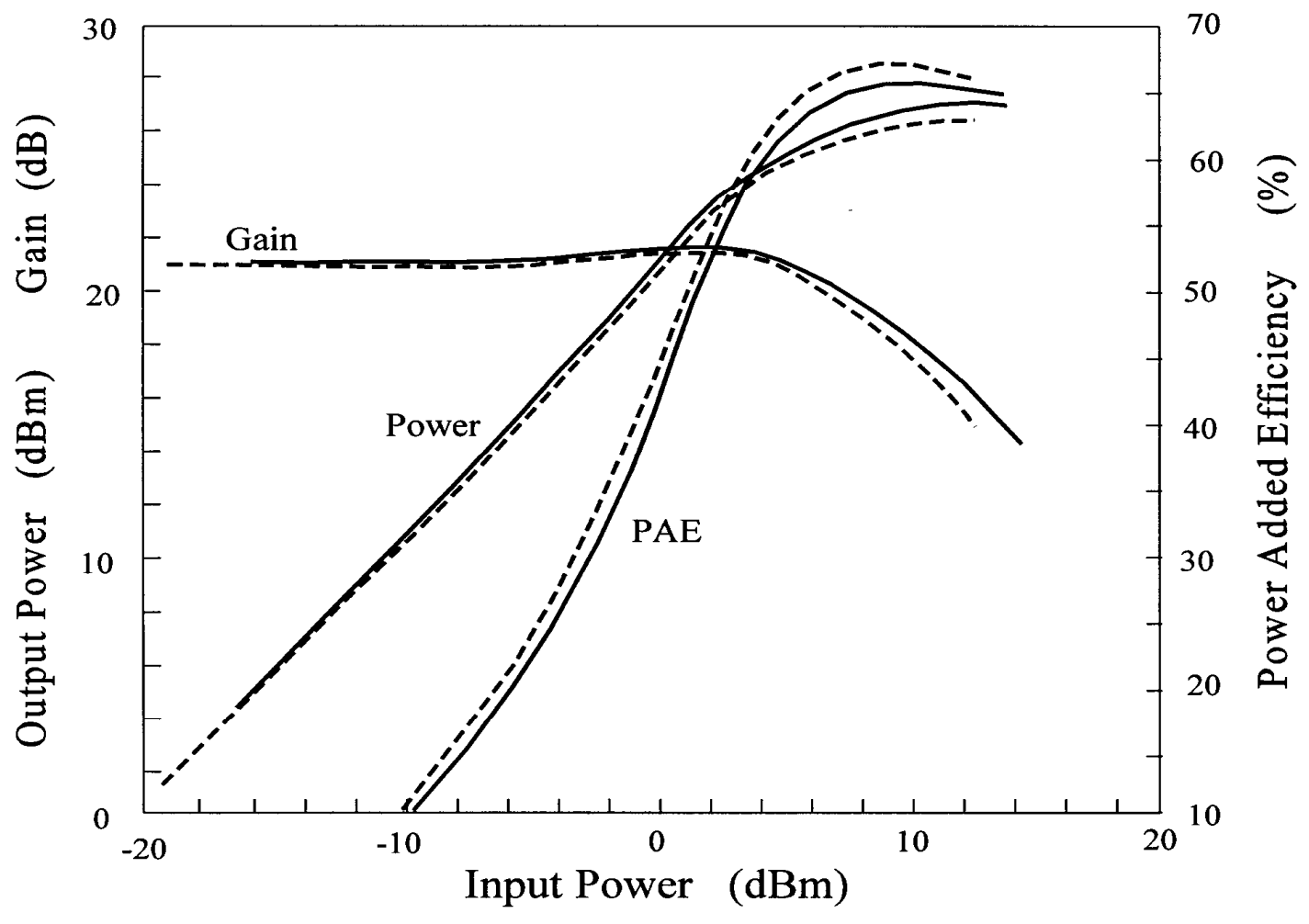


Figure 11

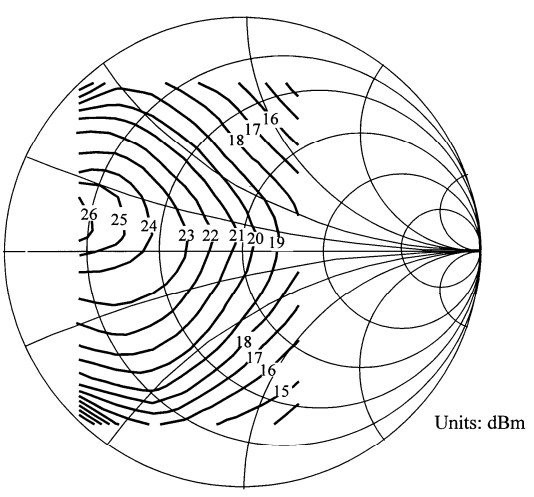

(a)

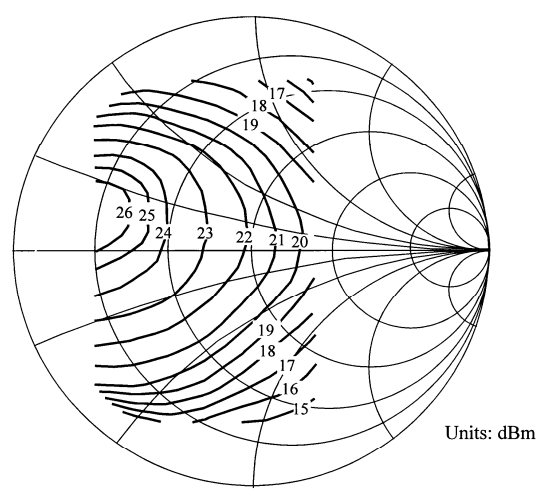

(b)

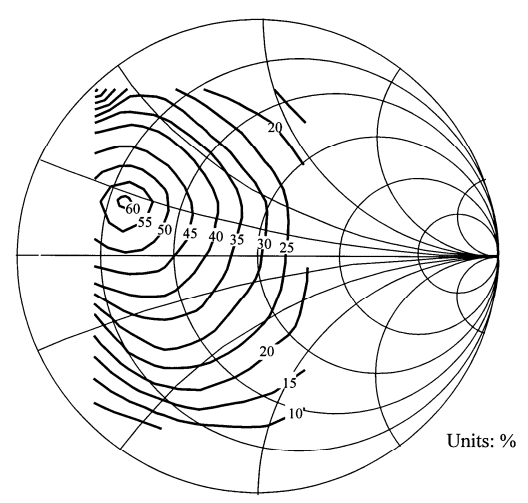

(c)

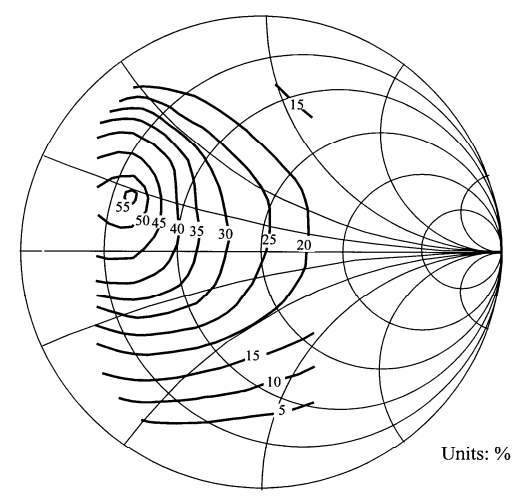

(d) 
Figure 12

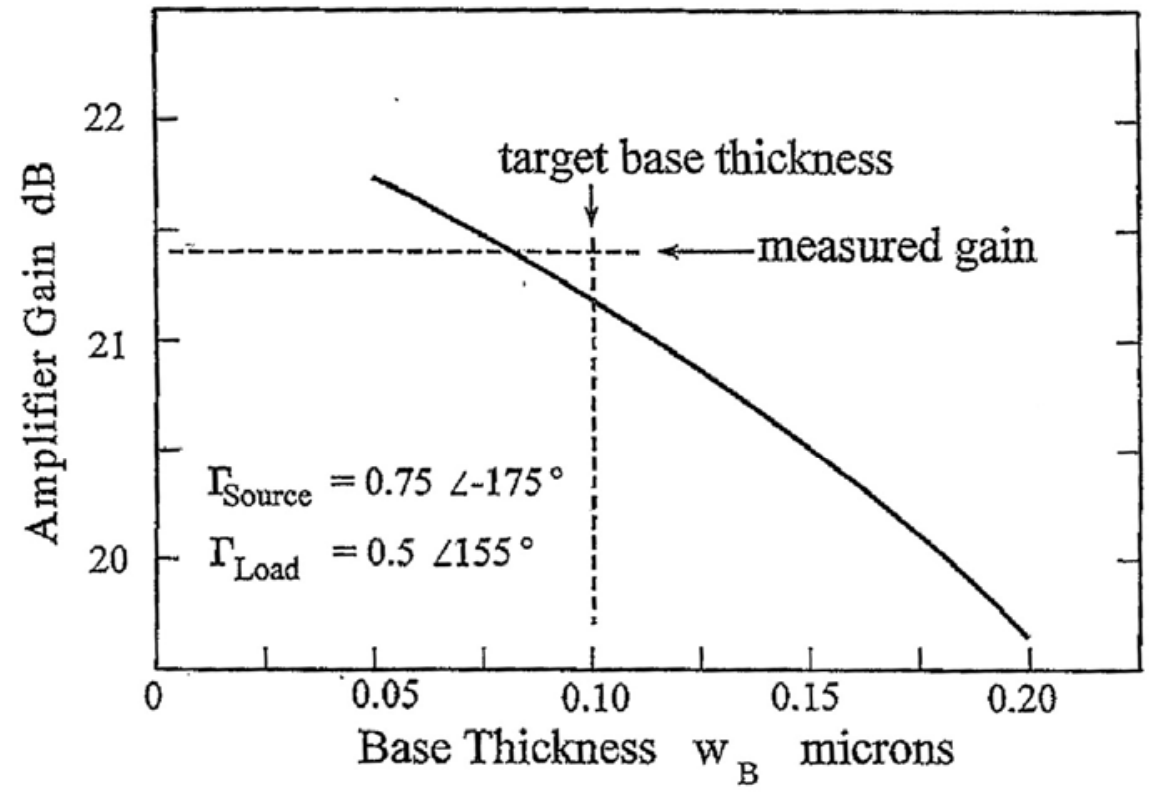

